\title{
Inhibition of Cytochrome P450 Enzymes by Drugs-Molecular Basis and Practical Applications
}

\author{
F. Peter Guengerich* \\ Department of Biochemistry, Vanderbilt University School of Medicine, Nashville, TN 37232-0146, USA
}

\begin{abstract}
Drug-drug interactions are a major cause of hospitalization and deaths related to drug use. A large fraction of these is due to inhibition of enzymes involved in drug metabolism and transport, particularly cytochrome P450 (P450) enzymes. Understanding basic mechanisms of enzyme inhibition is important, particularly in terms of reversibility and the use of the appropriate parameters. In addition to drug-drug interactions, issues have involved interactions of drugs with foods and natural products related to P450 enzymes. Predicting drug-drug interactions is a major effort in drug development in the pharmaceutical industry and regulatory agencies. With appropriate in vitro experiments, it is possible to stratify clinical drug-drug interaction studies. A better understanding of drug interactions and training of physicians and pharmacists has developed. Finally, some P450s have been the targets of drugs in some cancers and other disease states.
\end{abstract}

Key Words: Cytochrome P450, CYP, Drug-drug interactions, P450 inhibition, Enzyme inhibition

\section{INTRODUCTION TO DRUG-DRUG INTERACTIONS}

Drug-drug interactions are important and accordingly are a major issue in the advancement of new chemical entities to patients. In one study (Montané et al., 2018), drug-related deaths accounted for $7 \%$ of all deaths in hospital settings. Drug-drug interactions are an issue in this regard. Although some pharmacodynamic issues are involved, a large fraction of the drug-drug interactions is pharmacokinetic in nature.

A general overview of the interactions of a chemical with an enzyme is shown in Fig. 1A, where an enzyme involved in the metabolism of a drug is considered. The drug is converted to a product, often called a metabolite. With respect to the parent drug molecule, the product may have unaltered pharmacological activity, lose some or all of its pharmacological activity, be even more active, or be toxic. In the interactions of two drugs, one is sometimes termed the "perpetrator" and one the "victim" (Fig. 1B). In some cases, drug interaction due to enhanced metabolism by induction or allosteric activation may be seen and have clinical consequences (Bolt et al., 1977), but the focus here will be on competitive and irreversible inhibitors that attenuate drug metabolism (as "perpetrators").

Recently Yu et al. (2018) evaluated drug-drug interactions in 103 recent drug approvals by the United States Food and Drug Administration (FDA). Of these, 45 were involved as victims (substrates) in interactions with marketed drugs (perpetrators). The therapeutic classes are shown in Fig. 2A, with cancer treatments accounting for more than 1/4. The enzymes involved are primarily cytochrome P450 and transporter enzymes (Fig. 2B), with P450 3A4/5 involved in $~ 2 / 3$ of the interactions. Of the 103 new drugs, 20 were acting as perpetrators to some extent (Yu et al., 2018), with P450 3A4/5 and $\mathrm{P}$-glycoprotein again being the most prominent enzymes (Fig. 1B). Accordingly, this review will focus on issues of inhibition of P450 3A4 (In general P450 3A4 and 3A5 have similar substrate specificity and are sensitive to the same inhibitors, with some important exceptions (Hardy et al., 2014; Zhu et al., 2014; Kramlinger et al., 2015), but many experiments with drugs were done only with P450 3A4-or 3A4 and 3A5 were not discriminated - and will be referred to as $3 A 4$ in that context).

\section{BACKGROUND ON P450S}

P450s enzymes are the main catalysts involved in the oxidation of chemicals in general (Rendic and Guengerich, 2015), including drugs. The same is true for involvement in

\section{Open Access https://doi.org/10.4062/biomolther.2021.102}

This is an Open Access article distributed under the terms of the Creative Commons Attribution Non-Commercial License (http://creativecommons.org/licenses/by-nc/4.0/) which permits unrestricted non-commercial use, distribution, and reproduction in any medium, provided the original work is properly cited.
Received Jun 22, 2021 Accepted Jul 22, 2021

Published Online Sep 3, 2021

*Corresponding Author

E-mail: f.guengerich@vanderbilt.edu

Tel: +1-615-322-2261, Fax: +1-615-343-0704 


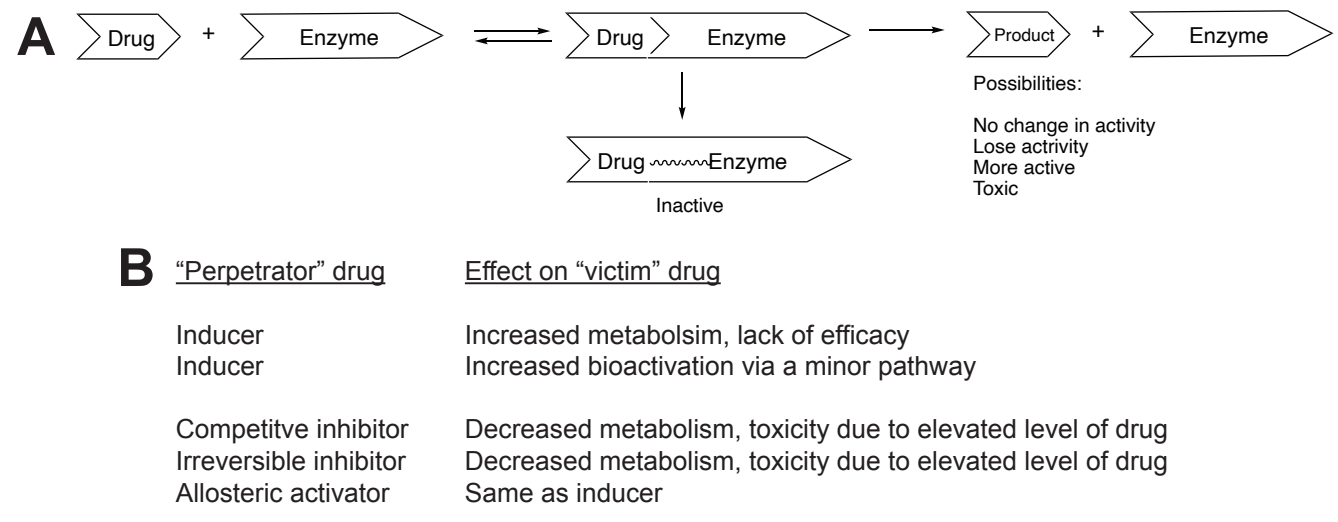

Fig. 1. (A) General scheme for interaction of a drug with an enzyme involved in its metabolism. (B) Interactions of "perpetrator" and "victim" drugs.

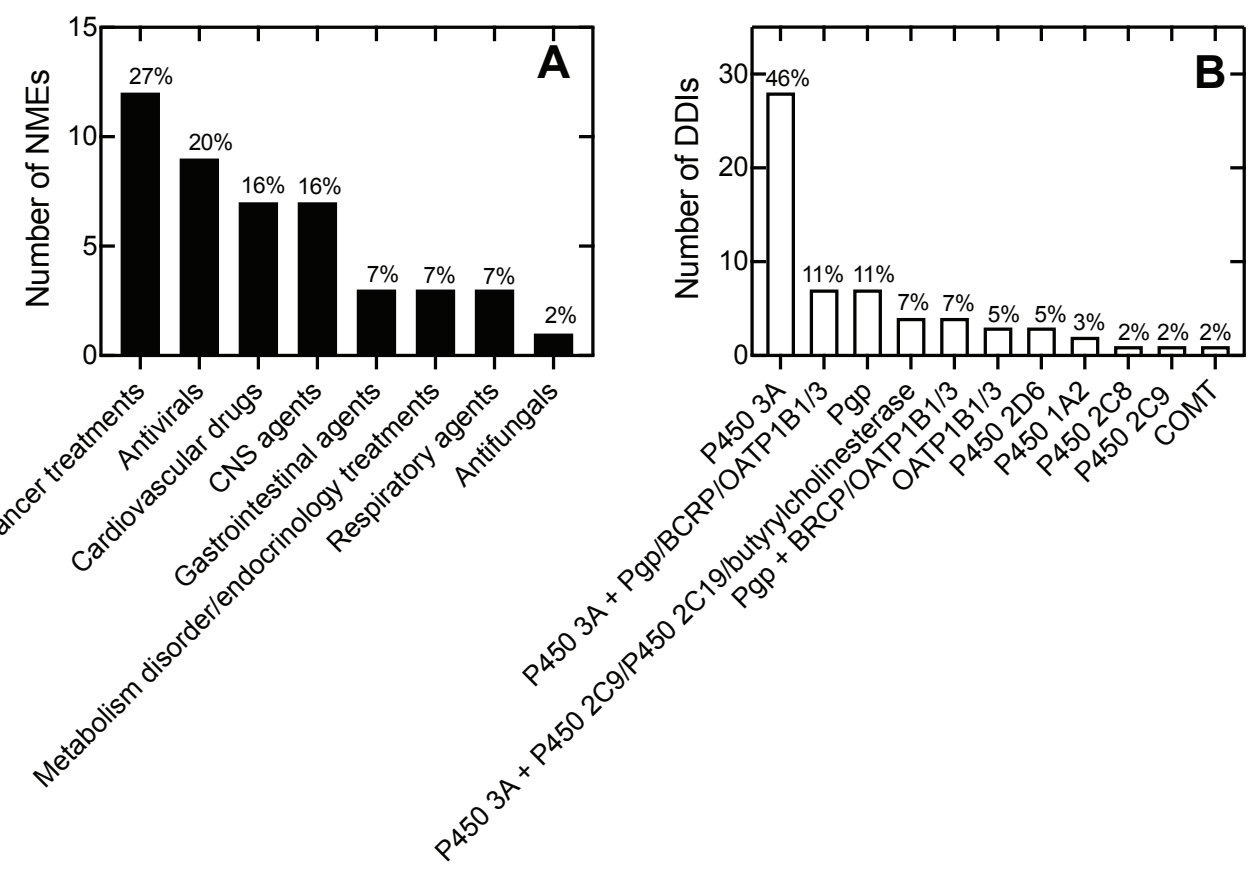

Fig. 2. Frequency of new molecular entities (NMEs, i.e. new drug candiddates) in inhibition-based drug-drug interactions (DDIs) with drugs approved by the Food and Drug Administration (FDA) in the United States between 2013 and 2016 (Yu et al., 2018). (A) Grouping by therapeutic class. (B) Grouping by enzymes involved. Pgp and OAT1B1 are transporters. COMT: catechol O-methyl transferase.

steroid metabolism (Auchus and Miller, 2015). The history of P450 research can be traced to the 1940s and the interest in the metabolism of drugs, steroids, and carcinogens (Williams, 1947; Mueller and Miller, 1948; Ryan, 1959), but the actual discovery of P450 as an entity developed from biochemical interests in the spectral properties of liver cytochromes (Omura and Sato, 1962, 1964). For the history of the characterization of P450s, elucidation of chemical mechanisms of catalysis, gene regulation, pharmacogenetics, and development of the understanding of roles in drug metabolism and deposition, see (Ortiz de Montellano, 2015; Guengerich, 2019b; Parkinson et al., 2019).

With the development of the Human Genome Project, it was established that there are 57 human P450 (CYP) genes
(Table 1). Whether some of these are expressed at appreciable levels (e.g., 2A7, 3A43) is yet unclear, but there are two splice variants of P450 4F3 expressed, so the number of human P450s is still $\sim 57$. Several of the P450s remain largely uncharacterized in terms of function and can be considered "orphans" in the context of a classification of P450s by substrate (Table 1).

Some of the reactions shown to be catalyzed by P450s are slow and may not be indicative of more relevant reactions that the enzyme might be doing (e.g., P450 2S1, 2U1, 4X1) (Fekry et al., 2019). Some P450s could be grouped under multiple headings (e.g., 1B1—steroids (estrogens) and xenobiotics (polycyclic hydrocarbons)). As a corollary, some of the P450s that are recognized for their roles in the metabolism of en- 
Table 1. Classification of human P450s based on major substrate class

\begin{tabular}{|c|c|c|c|c|c|}
\hline Steroids & Xenobiotics & Fatty acids & Eicosanoids & Vitamin & Unknown \\
\hline $1 \mathrm{~B} 1^{*}$ & $1 \mathrm{~A} 1^{*}$ & $2 \mathrm{~J} 2$ & $2 \mathrm{U} 1$ & $2 \mathrm{R} 1^{*}$ & $2 \mathrm{~A} 7$ \\
\hline $7 A 1^{*}$ & $1 \mathrm{~A} 2^{*}$ & $2 S 1$ & $4 \mathrm{~F} 2$ & $24 \mathrm{~A} 1^{* *}$ & $4 \times 1$ \\
\hline 7B1 & $2 A 6^{*}$ & $2 \mathrm{U} 1$ & $4 \mathrm{~F} 3$ & 26B1 & $20 \mathrm{~A} 1$ \\
\hline 8B1 & $2 \mathrm{~A} 13^{*}$ & $4 \mathrm{~A} 11$ & $4 \mathrm{~F} 8$ & $26 \mathrm{C} 1$ & \\
\hline $11 \mathrm{~A} 1^{*}$ & $2 \mathrm{~B} 6^{*}$ & $4 \mathrm{~A} 22$ & $5 \mathrm{~A} 1$ & 27B1 & \\
\hline 11B1* & $2 \mathrm{C} 8^{*}$ & $4 \mathrm{~B} 1^{\text {** }}$ & $8 \mathrm{~A} 1^{*}$ & $27 \mathrm{C} 1$ & \\
\hline 11B2* & $2 \mathrm{Cg} *$ & $4 \mathrm{~F} 11$ & & & \\
\hline $17 \mathrm{~A} 1^{*}$ & 2C18 & $4 \mathrm{~F} 12$ & & & \\
\hline $19 \mathrm{~A} 1^{*}$ & $2 \mathrm{C} 19^{*}$ & $4 \mathrm{~F} 22$ & & & \\
\hline $21 \mathrm{~A} 2^{*}$ & $2 \mathrm{D} 6^{*}$ & $4 \mathrm{~V} 2$ & & & \\
\hline $27 \mathrm{~A} 1$ & $2 \mathrm{E} 1^{*}$ & $4 Z 1$ & & & \\
\hline $39 A 1$ & $2 \mathrm{~F} 1$ & & & & \\
\hline $46 \mathrm{~A} 1^{*}$ & $2 \mathrm{~W} 1$ & & & & \\
\hline \multirow[t]{4}{*}{$51 \mathrm{~A} 1^{*}$} & $3 A 4^{*}$ & & & & \\
\hline & $3 \mathrm{~A} 5^{*}$ & & & & \\
\hline & $3 \mathrm{~A} 7^{*}$ & & & & \\
\hline & $3 \mathrm{~A} 43$ & & & & \\
\hline
\end{tabular}

This classification is somewhat arbitrary in some cases, e.g., P450s $1 \mathrm{~B} 1$ and $27 \mathrm{~A} 1$ could be grouped in either of two different categories.

${ }^{*}$ Crystal structure available. ${ }^{* *}$ Crystal structure of animal orthologue available.

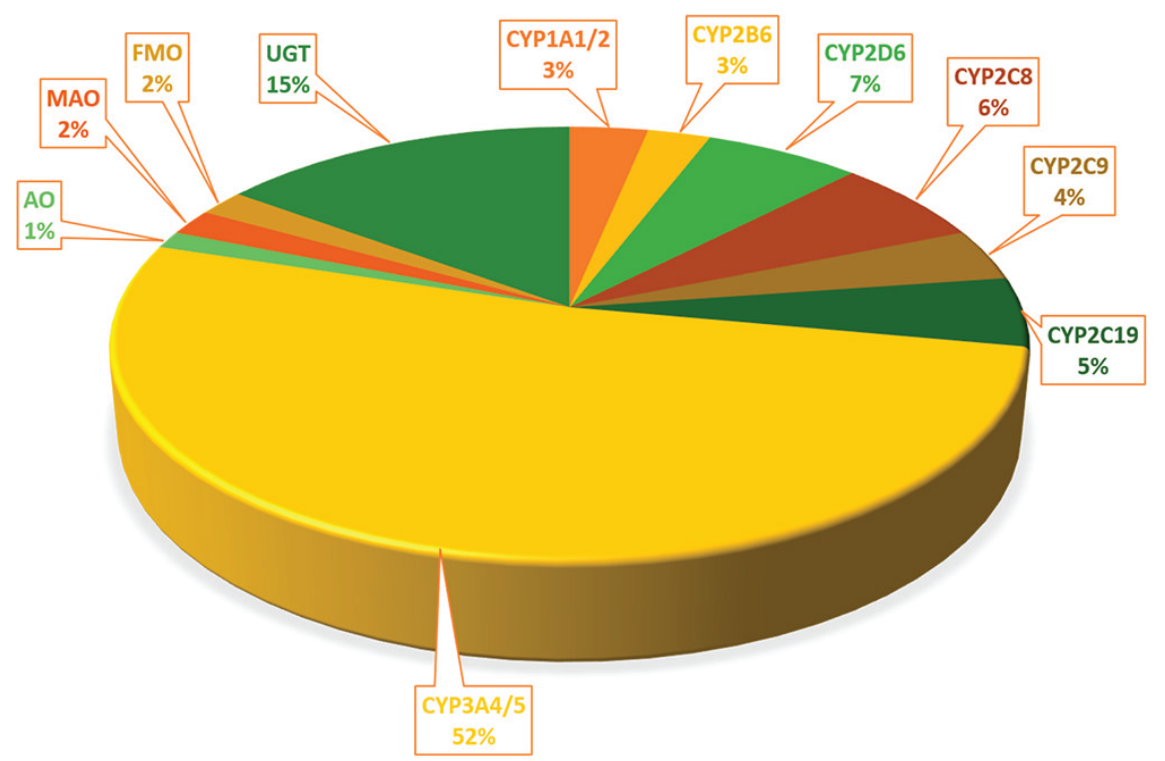

Fig. 3. Fractions of small molecule drugs approved by US FDA in 2015-2020 metabolized by individual enzymes (Bhutani et al., 2021). UGT: uridine glucuronyl transferase; FMO, flavin-containing monooxygenase; AO, aldehyde oxidase. Reprinted from J. Med. Chem., Vol. 64, Bhutani, P., Joshi, G., Raja, N., Bachhav, N., Rajanna, P. K., Bhutani, H., Paul, A. T. and Kumar, R., US FDA approved drugs from 2015June 2020: a perspective, pages 2339-2381 (Bhutani et al., 2021), Copyright (2021), with permission from American Chemical Society.

dogenous compounds can also act on xenobiotic chemicals, including drugs or drug candidates, e.g. P450 11A1 (Zhang et al., 2012).

Five P450s in the xenobiotics column (i.e., 1A2, 2C9, 2C19, 2D6, 3A4) have historically accounted for $\sim 90 \%$ of the P450 reactions with drugs, and $\mathrm{P} 450$ s have been the main enzymes involved in the metabolism of (small molecule) drugs (Rendic and Guengerich, 2015; Bhutani et al., 2021). The overall situation has not changed over the years, but pharmaceuti- cal companies have tried to reduce the fraction of metabolism done by the highly polymorphic P450s, mainly P450s 2D6 and 2C19 (Fig. 3). Perhaps because of this, an even larger fraction of drugs now seems to be metabolized largely by P450 3A4 (Fig. 3). This trend has some consequences in the potential for drug-drug interactions, as described below.

Beginning in the 1980s, it became possible to use in vitro methods to discern which drugs are substrates, inhibitors, and inducers of individual P450s (Guengerich, 1989). Such predic- 
Table 2. Inhibitors of major P450s

\begin{tabular}{|c|c|c|c|c|}
\hline $1 \mathrm{~A} 2$ & $2 \mathrm{Cg}$ & 2C19 & 2D6 & $3 A 4$ \\
\hline Amiodarone & Amiodarone & Chloramphenicol & Amiodarone & Amiodarone \\
\hline Cimetidine & Capecitabine & Cimetidine & Bupropion & Aprepitant \\
\hline Ciprofloxacin & Clopidogrel & Citalopram & Celecoxib & Atomoxetine \\
\hline Citalopram & Crisaborole & Esomeprazole & Chlorpheniramine & Boceprevir \\
\hline Crisaborole & Efavirenz & Felbamate & Chlorpromazine & Chloramphenicol \\
\hline Efavirenz & Fenofibrate & Fluoxetine & Cimetidine & Cimetidine \\
\hline Fluoroquinolone & Fluconazole & Fluvoxamine & Cinacalcet & Ciprofloxacin \\
\hline Fluvoxamine & Fluvastatin & Indomethacin & Citalopram & Clarithromycin \\
\hline Furafylline & Fluvoxamine & Isoniazid & Clemastine & Delaviridine \\
\hline Interferon & Isoniazid & Ketoconazole & Clomipramine & Diethyldithiocarbamate \\
\hline Methoxsalen & Lovastatin & Lansopraxole & Cocaine & Diltiazem \\
\hline Mibefradil & Metronidazole & Modafinil & Diphenhydramine & Erythromycin \\
\hline Ribociclib & Paroxetine & Omeprazole & Doxepin & Esomeprazole \\
\hline Rucaparib & Phenylbutazone & Oxcarbazepine & Doxorubicin & Fluconazole \\
\hline \multirow[t]{27}{*}{ Ticlopidine } & Probenicid & Pantoprazole & Duloxetine & Fluvoxamine \\
\hline & Rucaparib & Probenicid & Escitalopram & Gestodene \\
\hline & Sertraline & Rucaparib & Fluoxetine & Grapefruit juice \\
\hline & Sulfamethoxazole & Ticlopidine & Halofantrine & Idelalisib \\
\hline & Sulfaphenazole & Ropiramate & Haloperidol & Imatinib \\
\hline & Teniposide & Voriconazole & Hydroxyzine & Indinavir \\
\hline & Voriconazole & & Levomepromzaine & Itraconazole \\
\hline & Zafirlukast & & Methadone & Ketoconazole \\
\hline & & & Metoclopramide & Lesinurad \\
\hline & & & Mibefradil & Mibefradil \\
\hline & & & Midodrine & Mifepristone \\
\hline & & & Moclobemide & Nefazodone \\
\hline & & & Palonosetron & Nelfinavir \\
\hline & & & Panobinostat & Netupitant \\
\hline & & & Paroxetine & Norfloxacin \\
\hline & & & Perphenazine & Norfluoxetine \\
\hline & & & Promethazine & Omeprazole \\
\hline & & & Quinidine & Pantoprazole \\
\hline & & & Ranitidine & Regorafenib \\
\hline & & & Riclopidine & Ribociclib \\
\hline & & & Ritonavir & Ritonavir \\
\hline & & & Rolapitant & Saquinavir \\
\hline & & & Rucaparib & Starfruit \\
\hline & & & Sertraline & Telaprevir \\
\hline & & & Terbinafine & Telithromycin \\
\hline & & & Tripelennamine & Verapamil \\
\hline & & & & Voriconazole \\
\hline
\end{tabular}

Modified from Flockhart, D. A. Drug Interactions: Cytochrome P450 Drug Interaction Table. Indiana University School of Medicine (2007). "https://drug-interactions.medicine.iu.edu" Accessed 27 August 2021 (Flockhart, 2007).

tions can be confirmed in humans in vivo in many cases. Of relevance to this review, a list of inhibitors of five major human P450s involved in drug metabolism was prepared by the late Prof. David Flockhart, and a website is maintained at Indiana University (Table 2). This information can be very useful to pharmacists and physicians who prescribe medicine and fill prescriptions (as well as those involved in drug development).

\section{TYPES OF INHIBITION}

It is useful to review basic information about enzyme in- hibition before delving into some of the specifics with P450s (Table 3).

Reversible inhibition is usually taught in basic biochemistry courses. The competitive, non-competitive, and uncompetitive modes can be distinguished (at least in principle) by their characteristic double-reciprocal plots as a function of substrate concentrations (Fig. 4). Other useful plots involve varying inhibitor concentration (e.g., Dixon plots) (Dixon and Webb, 1964; Kuby, 1991).

A few points are in order here before proceeding. First, double-reciprocal plots can be useful for qualitative examination of types of inhibition but they should not be used for calcula- 
A. Competitive
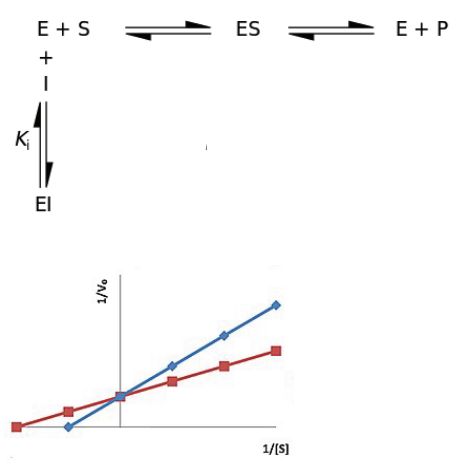

B. Non-competitive
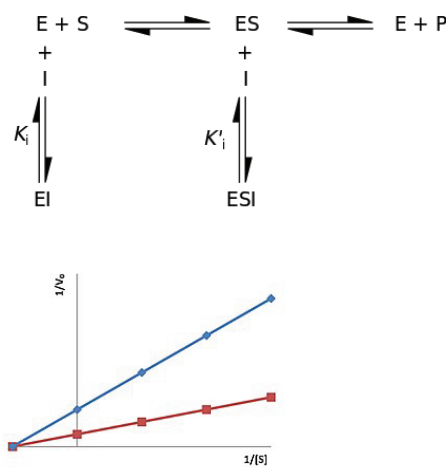

\section{Uncompetitive}
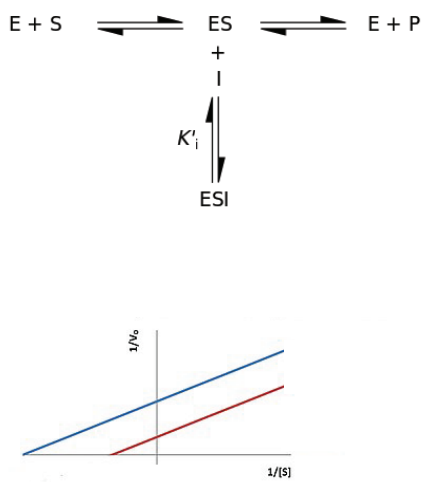

Fig. 4. Idealized models for reversible enzyme inhibition. Lineweaver-Burk plots (1/v vs. 1/[S]) are shown for each: uninhibited reaction (red points and line); inhibited reaction (blue points and line).

Table 3. Types of Inhibition

\begin{tabular}{l}
\hline Reversible \\
Competitive \\
Non-competitive \\
Uncompetitive \\
Mixed \\
Time-dependent (“irreversible") \\
Formation of inhibitory product \\
Electrophile or radical \\
ROS \\
Metabolite complex (-N=O or C:) (nitroso or carbene) \\
Mechanism-based \\
Slow, tight-binding \\
\hline
\end{tabular}

tion of parameters $\left(k_{\mathrm{cat}}, K_{\mathrm{m}}, k_{\mathrm{cat}} / K_{\mathrm{m}}\right)$ because they are based on in appropriate weighting of data obtained with low substrate concentrations (Johnson, 2019). Second, these are idealized situations and may well not reveal enzyme complexity. For instance, the inhibition of P450-catalyzed oxidation of nifedipine or quinidine by cholesterol appears to follow non-competitive kinetics but it is known that cholesterol itself is a substrate (4 $\beta$-hydroxylation) (Shinkyo and Guengerich, 2011). That is, cholesterol is both a substrate and an inhibitor. An explanation is that the large active site of P450 3A4 allows both occupancy by both cholesterol and another substrate, with cholesterol either binding in the substrate site or elsewhere nearby (Fig. 5). This is an adaptation of a more general mechanism proposed by Segel (1975). Finally, "mixed" inhibition is involved when the intercept of the two lines (no inhibitor, plus inhibitor) in Fig. 4 is to the left of the $x=0$ axis but not on the $y=0$ axis. This is generally assumed to mean that neither of the two reactions shown for binding the inhibitor I in Fig. 4B is predominating, i.e. binding to free enzyme $(E)$ or the enzyme-substrate complex (ES). However, the mechanism may be more complex and more detailed analysis is probably in order. Steady-state methods are really only a prelude into mechanistic studies, and pre-steady-state approaches are more powerful if they can be applied (Johnson, 2019).

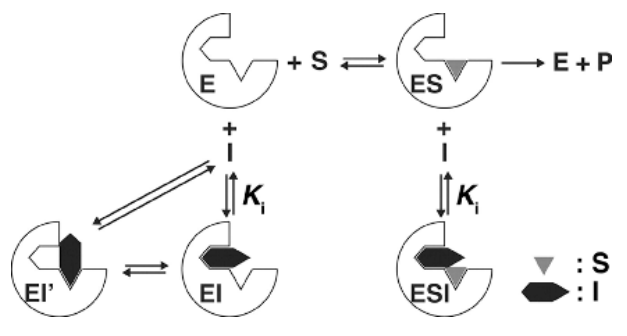

Fig. 5. Proposed model for apparent non-competitive inhibition of P450 3A4 oxidation activities by the substrate cholesterol (Segel, 1975; Shinkyo and Guengerich, 2011): E, P450 3A4; I, cholesterol; $\mathrm{S}$, substrate; El, P450 3A4-cholesterol complex; El', P450 3A4cholesterol complex catalyzing cholesterol $4 \beta$-hydroxylation; ES, P450 3A4-substrate complex; ESI, P450 3A4-substrate-cholesterol complex. Reprinted from J. Biol. Chem., Vol. 286, Shinkyo, R. and Guengerich, F. P., Inhibition of human cytochrome P450 3A4 by cholesterol, pages 18426-18433 (Shinkyo and Guengerich, 2011), Copyright (2011), with permission from Elsevier.

Competitive inhibition can often be problematic. For instance, kinetic simulations clearly show that the order of addition of substrate and inhibitors can change the apparent outcome inhibition constant $\left(K_{i}\right)$, and the effect of the order is more pronounced with a strong inhibitor or with time-dependent inhibition (Guengerich, 2019a). Substrate depletion can alter parameters $\left(K_{m}\right)$ and even generate apparently sigmoidal plots. A rate-limiting step following product formation lowers the apparent $K_{\mathrm{m}}$ and also distorts the observed $K_{\mathrm{i}}$. The consumption of an inhibitor during a reaction affects the apparent $K_{\mathrm{i}}$, the extent of which differs depending on which enzyme is involved-the target or another enzyme consuming the inhibitor.

In contrast to reversible inhibition, irreversible inhibition reactions are time-dependent and are of several types (Table 3 ). In one case, a P450 generates a reactive product that can react with that $P 450$ and perhaps with other molecules as well. One example is chloramphenicol, where the hydroxylation of a $-\mathrm{CHCl}_{2}$ moiety yields a gem-halohydrin $(-\mathrm{CH}(\mathrm{OH}) \mathrm{Cl})$ and then an acyl chloride $(-\mathrm{C}(\mathrm{O}) \mathrm{Cl})$, which reacts with lysines (Halpert and Neal, 1980). In this regard, one can also consider prod- 


$$
\begin{aligned}
& \text { A } \mathrm{E}+\mathrm{S} \underset{k_{-1}}{\stackrel{k_{1}}{\rightleftarrows}} \mathrm{ES} \stackrel{k_{2}}{\longrightarrow} \mathrm{EP} \underset{k_{-3}}{\stackrel{k_{3}}{\rightleftarrows}} \mathrm{E}+\mathrm{P} \\
& k_{4} \mid k_{-4} \\
& \begin{array}{ll}
E^{\prime} S & k_{-4}=0 \text { : Irreversible } \\
k_{-4}>0 \text { : Slow tight binding inhibition }
\end{array} \\
& \text { B } \quad \mathrm{E}+\mathrm{S} \underset{k_{-1}}{\stackrel{k_{1}}{\rightleftarrows}} \mathrm{ES} \stackrel{k_{2}}{\longrightarrow} \mathrm{EP} \underset{k_{-3}}{\stackrel{k_{3}}{\rightleftarrows}} \mathrm{E}+\mathrm{P} \\
& \mathrm{E}+\mathrm{I} \underset{k_{-4}}{\stackrel{k_{4}}{\rightleftarrows}} \text { El } \underset{k_{-5}}{\stackrel{k_{5}}{\rightleftarrows}} \text { EI } \quad \begin{array}{l}
k_{-5}=0 \text { : Irreversible } \\
k_{-5}>0 \text { : Slow tight binding inhibition }
\end{array}
\end{aligned}
$$

Fig. 6. Kinetic models for irreversible inhibition. (A) The substrate $S$ acts as the inhibitor; (B) a second molecule I is the inhibitor. The values of the indicated rate constants distinguish between true irreversible inhibition and slow, tight-binding ("slow onset") inhibition (Johnson, 2019).

ucts of oxygen to be inhibitory products, i.e. reactive oxygen species $\left(\mathrm{O}_{2}{ }^{-}, \mathrm{H}_{2} \mathrm{O}_{2}\right)$. Some P450s (e.g., 4A11) appear to be very sensitive to this phenomenon, with conversion of the thiolate group normally liganded to the heme being oxidized to a sulfenic acid (Albertolle et al., 2017, 2018, 2019).

A special case is the production of $\mathrm{C}$-nitroso and carbene products, where the product binds tightly to the heme iron (in its ferrous form). Sometimes this phenomenon has been termed "metabolite inhibition" (complexation). The most common cases where this happens are with primary amines (which may be generated from secondary or tertiary amines) and methylenedioxyphenyl compounds that yield carbenes. These complexes are recognized by their characteristic Soret spectra at $455 \mathrm{~nm}$ that form during the reactions (Franklin and Buening, 1974; Mansuy et al., 1979; Paulsen-Sörman et al., 1984).

Another type of time-dependent irreversible inhibition is true mechanism-based inactivation (Fig. 6). This is distinguished from the generation of reactive products in that a reactive entity is generated in the course of the reaction but does not leave the enzyme (Abeles and Maycock, 1976; Silverman, 1995). Such inhibition, in contrast to generation of reactive products, is distinguished by the lack of attenuation by nucleophilic scavengers, e.g. glutathione. In many cases the products of the reaction with the $\mathrm{P} 450$ protein (or its heme prosthetic group) have been identified (Correia and Hollenberg, 2015; Lin et al., 2018). An important example is bergamottin, a component of grapefruit juice responsible for interaction with P450 3A4 (Bailey et al., 1990; He et al., 1998; Lin et al., 2012) (vide infra).

Yet another type of time-dependent enzyme inhibition is called slow, tight-binding inhibition (Silverman, 1995) or slowonset inhibition (Johnson, 2019) (Fig. 6). In this case a "loose" binding of the inhibitor and enzyme occurs but that binding leads to the conversion of the enzyme to a form that binds the inhibitor more tightly. This phenomenon can be distinguished from mechanism-based inactivation by its reversibility, even if it is slow (Fig. 6). Mechanism-based inhibition is common with P450s but apparently slow, tight-binding inhibition is not, at least to date. The latter phenomenon has been used to explain the inhibition of P450 17A1 by abiraterone (Cheong et al., 2020) but has not been confirmed in our own laboratory (Guengerich et al., 2021) or others (Petrunak et al., 2017).
Table 4. Approaches to analyzing enzyme inhibition in order of increasing complexity of experiments

\begin{tabular}{l}
\hline Single point inhibition assay \\
$\mathrm{IC}_{50}$ \\
$K_{\mathrm{i}}$ \\
Time-dependent inhibition \\
Time-dependent $K_{\text {inactivation }}$ and $K_{\mathrm{i}}$ \\
\hline
\end{tabular}

\section{ISSUES OF TIME-DEPENDENT INHIBITION}

High-throughput screening for reversible inhibition (or at least medium throughput) is relatively straightforward. Although fluorescence and luminescence reactions have been developed for individual human P450s, the results have been problematic in that the response patterns have not been very consistent with known substrates, especially with P450 3A4 (Bjornsson et al., 2003a, 2003b; Shou and Dai, 2008). Thus, most pharmaceutical companies use assays with FDA-recommended substrates, e.g. phenacetin for P450 1A2, diclofenac for P450 2C9, (S)-mephenytoin for P450 2C19, dextromethorphan for P450 2D6, and testosterone and midazolam for P450 3A4 (Shou and Dai, 2008; Alyamani et al., 2017). These assays usually involve HPLC and mass spectrometry. In general, the recommended substrate concentrations to use are near the $K_{m}$ values. Positive controls (with accepted inhibitors) should be done at concentrations low enough to be selective.

Typically, a battery for testing inhibition would be done in the order shown in Table 4, with the scientific content of the results-and the cost-increasing at each step. A $K_{\mathrm{i}}$ is superior to an $\mathrm{IC}_{50}$ in that the $\mathrm{IC}_{50}$ value will be dependent upon the substrate concentration, but a $\mathrm{K}_{\mathrm{i}}$ is not.

Time-dependent inhibition is problematic, for several reasons. This phenomenon gives rise to varying pharmacokinetics and is difficult to model, because of the issue of the time needed to synthesize new protein in vivo. The effects of repeated doses are hard to model.

Zimmerlin et al. (2011) surveyed Novartis drugs on the market; only $4 \%$ showed time-dependent inhibition, and another $3 \%$ showed strong but reversible inhibition (Fig. 7). However, $23 \%$ of "new chemical entities" (under development) showed 
A

Drugs

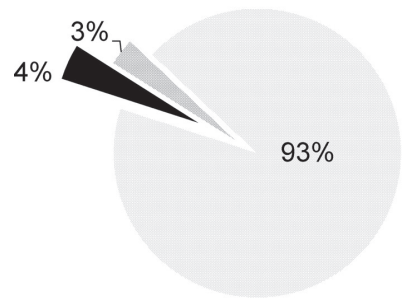

B

NCES

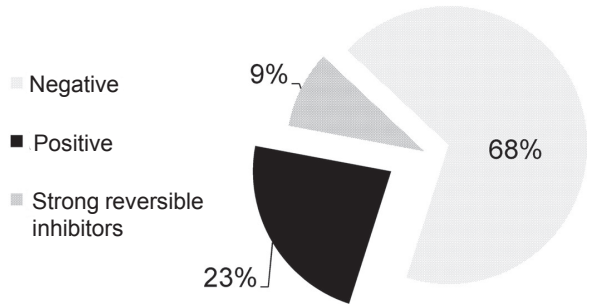

Fig. 7. Distribution of time-dependent inhibitor positive and negative compounds among Novartis (A) marketed drugs and (B) new chemical entities (i.e., drug candidates). The dark gray fraction represents strong ("high") reversible inhibition (Zimmerlin et al., 2011). Reprinted from Drug Metab. Dispos., Vol. 39, Zimmerlin, A., Trunzer, M. and Faller, B., CYP3A time-dependent inhibition risk assessment validated with 400 reference drugs, pages 1039-1046 (Zimmerlin et al., 2011), Copyright (2011), with permission from American Society for Pharmacology and Experimental Therapeutics.

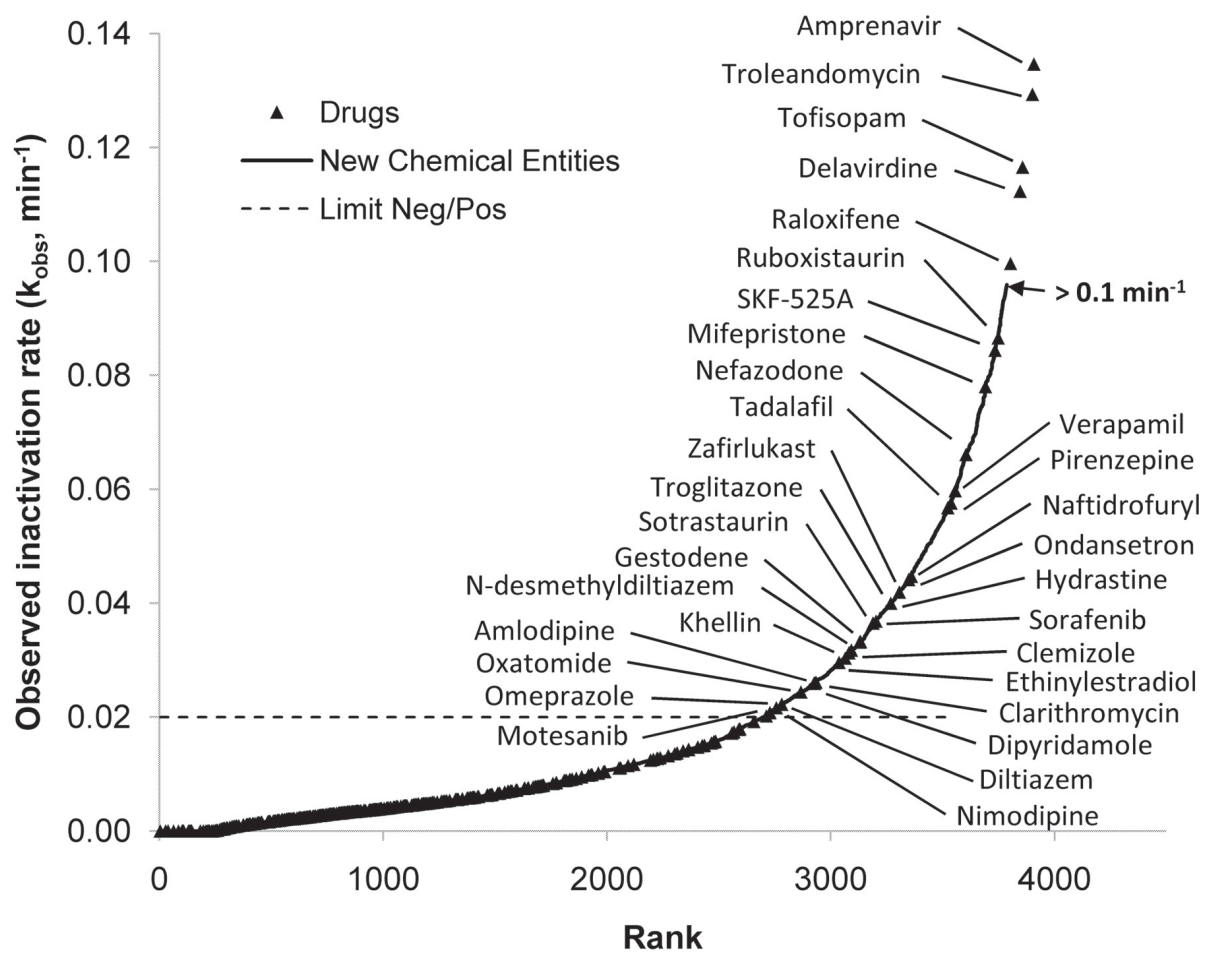

Fig. 8. Graphical representation of a series of test compounds ranked by rates of time-dependent inhibition ( $\left.k_{\mathrm{obs}}\right)$. The line includes new chemical entities (drug candidates), and marketed drugs are indicated with filled triangles ( $\mathbf{\Lambda})$ (Zimmerlin et al., 2011). Reprinted from Drug Metab. Dispos., Vol. 39, Zimmerlin, A., Trunzer, M. and Faller, B., CYP3A time-dependent inhibition risk assessment validated with 400 reference drugs, pages 1039-1046 (Zimmerlin et al., 2011), Copyright (2011), with permission from American Society for Pharmacology and Experimental Therapeutics.

time-dependent inhibition and 9\% were strong but reversible inhibitors (Zimmerlin et al., 2011), implying that strong and time-dependent inhibitors tend not to survive through the development process and get to market. A further analysis of time-dependent inhibitory drugs in shown in Fig. 8, ordered by the rate of inactivation. Although the mechanisms of some of these are known (e.g., $17 \alpha$-ethynylestradiol $\left(E_{2}\right)$, gestodene, troleandomycin), in other cases the chemistry underlying the inhibition is not very obvious. Similar experience at Pfizer has been reported (Fig. 9), with the incidence of in vitro time-de- pendent P450 3A4 inhibition being as high as $75 \%$ among candidates in many programs (Eng et al., 2021). As in the case of the Novartis compounds (Zimmerlin et al., 2011), many of these do not have chemical features typical of mechanismbased inactivation. The incidence of time-dependent inhibition was less in human hepatocytes than in liver microsomes, for reasons that are yet unknown. Even among the drugs that were time-dependent inhibitors of P450 3A4 in hepatocytes and in vivo, the structural reasons remain unclear.

Work with P450 3A4 in this laboratory has shown that the 

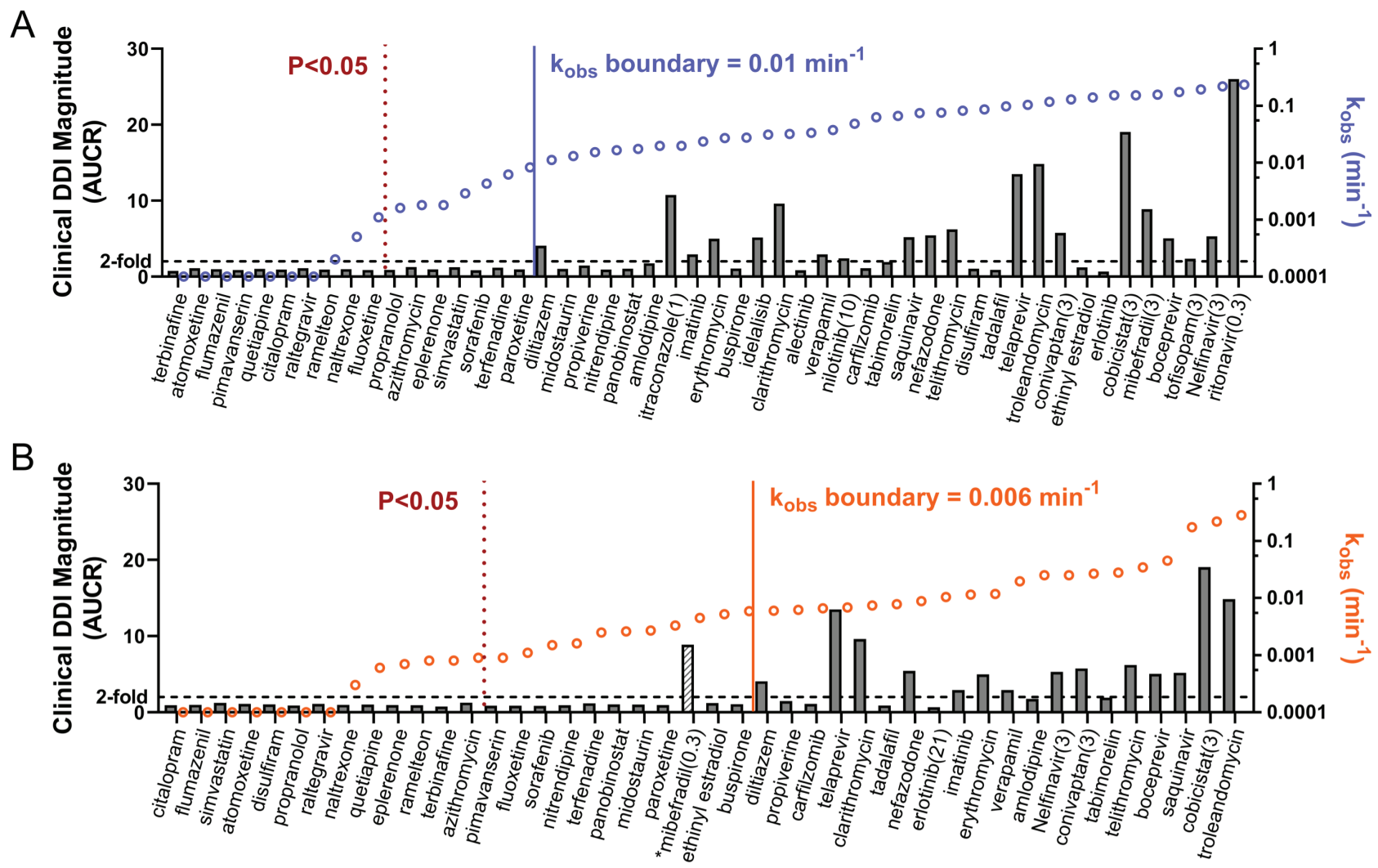

Fig. 9. Boundary line for $k_{\mathrm{obs}}$ for time-dependent inhibition and relation to in vivo drug-drug interactions (DDI) (Eng et al., 2021). (A) Fifty drugs were evaluated for P450 3A4 time-dependent inhibition in human liver microsomes (at $30 \mu \mathrm{M}$ unless noted otherwise) and ranked by $k_{\text {obs }}$, the first-order rate of inactivation, as judged using midazolam $1^{\prime}$-hydroxylation $(O)$, presented on a $\log _{10}$ scale (right $y$-axis). The filled bars show the in vivo drug-drug interactions as judged by the AUCR (AUC with the drug divided by the AUC without the drug, Clinical DDI magnitude). (B) The study in Part A was repeated in human hepatocytes. The stippled line indicates a 2-fold in vivo difference. Also indicated are $p<0.05$ statistical limits and a $k_{\text {obs }}$ "boundary" of the lowest in vitro value with 2-fold in vivo difference. Reprinted from Drug Metab. Dispos., Vol. 49, Eng, H., Tseng, E., Cerny, M. A., Goosen, T. C. and Obach, R. S., Cytochrome P450 3A time-dependent inhibition assays are too sensitive for identification of drugs causing clinically significant drug-drug interactions: a comparison of human liver microsomes and hepatocytes and definition of boundaries for inactivation rate constants, pages 442-450 (Eng et al., 2021), Copyright (2021), with permission from American Society for Pharmacology and Experimental Therapeutics.

interactions of many inhibitors with the enzyme is a multi-step process, as judged by the appearance of multiple spectral species over a period of up to 20 seconds or more (Guengerich et al., 2020). At least three individual complexes are observed en route to the final Type II complexes (Fig. 10A). The evidence indicates that the final complex is needed to achieve total inhibition of either 7-benzylquinolone O-dealkylation or testosterone $6 \beta$-hydroxylation. The inhibitory behavior is depicted in the traces in Fig. 10B, where the rate of 7-benzylquinoline O-debenzylation is not affected in the first 10 seconds after adding indinavir and then reaches an inhibited steady-state. The traces could be fit with a log-linear relationship, where the initial exponential phase involves first-order rearrangement of the initial P450 3A4-indinavir complex to the final $E^{*}$ I form (Fig. 10A).

One issue that was not addressed in our mechanistic work on P450 3A4 inhibition was whether both a substrate and inhibitor could present together in the "active site" (Fig. 10A), a question that arose earlier with cholesterol and nifedipine (and quinidine) (Fig. 5) (Shinkyo and Guengerich, 2011). Ketoconazole is a relatively large molecule (formula weight 531 ,
$630 \AA^{3}$ ), but an X-ray crystal structure of P450 3A4 showed occupancy by two ketoconazole molecules (Fig. 11) (Ekroos and Sjögren, 2006). To date, no P450 structures have been published with two different ligands present, although the possibility exists. Nevertheless, the size of the active site and the precedent with two ketoconazole molecules (Ekroos and Sjögren, 2006) indicate that this should be possible, making the kinetics even more complex.

Although P450 17A1 also showed similar sequences of spectral changes over a period of 10-30 seconds when binding inhibitors, inhibition proceeded very quickly (Child and Guengerich, 2020; Guengerich et al., 2021). This behavior was seen with several inhibitors, including abiraterone (Guengerich et al., 2021). The difference in behavior may be due to the large size of the active site (1400 $\AA^{3}$ (Yano et al., 2004)), compared to P450 17A1 (DeVore and Scott, 2012; Petrunak et al., 2014). Conclusions about one P450 do not necessarily apply to all others. 


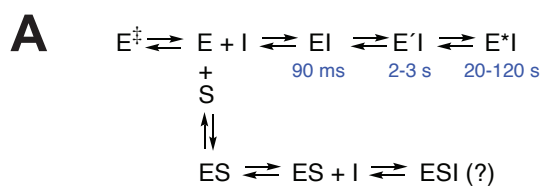

B

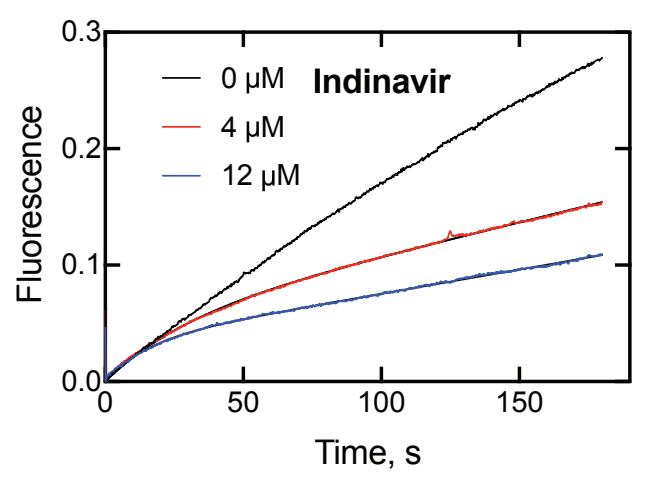

Fig. 10. Time-dependent inhibition of P450 $3 \mathrm{~A} 4$ by indinavir (Guengerich et al., 2020). (A) Conclusions about the stepwise inhibition of P450 3A4 with ketoconazole, clotrimazole, indinavir, itraconazole, and ritonavir ( $I$ in each case). $E, E^{\ddagger}, E^{\prime}$, and $E^{*}$ are conformationally distinct forms of the enzyme, P450 3A4. ESI is a complex containing both the substrate (S) and I but remains hypothetical at this time. The individual forms appear at the indicated times after mixing $\left(23^{\circ} \mathrm{C}\right)$. (B) Time-dependent inhibition of 7 -benzyloxyquinoline O-dealkylation by indinavir with P450 3A4 (Guengerich et al., 2020), with the indicated concentration of indinavir added at the start of the reaction. The $y$-axis indicates the fluorescence $\left(F_{410 / 510}\right.$, arbitrary units) associated with the formation of the product (7-hydroxyquinoline). Note the delayed onset of inhibition in the first $50 \mathrm{~s}$. Reprinted from J. Biol. Chem., Vol. 296, Guengerich, F. P., McCarty, K. D. and Chapman, J. G., Kinetics of cytochrome P450 3A4 inhibition by heterocyclic drugs defines a general sequential multistep binding process, page(s) 100223 (Guengerich et al., 2020), Copyright (2020), with permission from Elsevier.

\section{EXAMPLES OF ISSUES WITH P450 INHIBITION}

Terfenadine is a rather classic example of a drug-drug interaction problem. Seldane ${ }^{\circledR}$, containing terfenadine as the active ingredient, was the first non-sedating antihistamine on the market and by 1990 had been used by 100 million people world-wide (Thompson and Oster, 1996; Guengerich, 2014). In 1989 an arrhythmia was observed in an individual who took an intentional overdose and by 1990 this "torsade des pointes" was also observed in some individuals using the recommended dose (Woosley et al., 1993; Woosley, 1996). The problem was identified as an accumulation of terfenadine in the plasma of those affected (Honig et al., 1992), exacerbated by erythromycin. Ultimately at least 140 deaths were attributed to terfenadine (Rangno, 1997).

Our own laboratory demonstrated the involvement of P450 $3 \mathrm{~A} 4$ in the metabolism of terfenadine (Fig. 12) (Yun et al., 1993). This assignment was unknown at the time terfenadine was marketed, demonstrating how far both the P450 science and the regulatory expectations have advanced since then. Terfenadine has high affinity for the hERG potassium channel protein, which explains the undesired pharmacological effect.

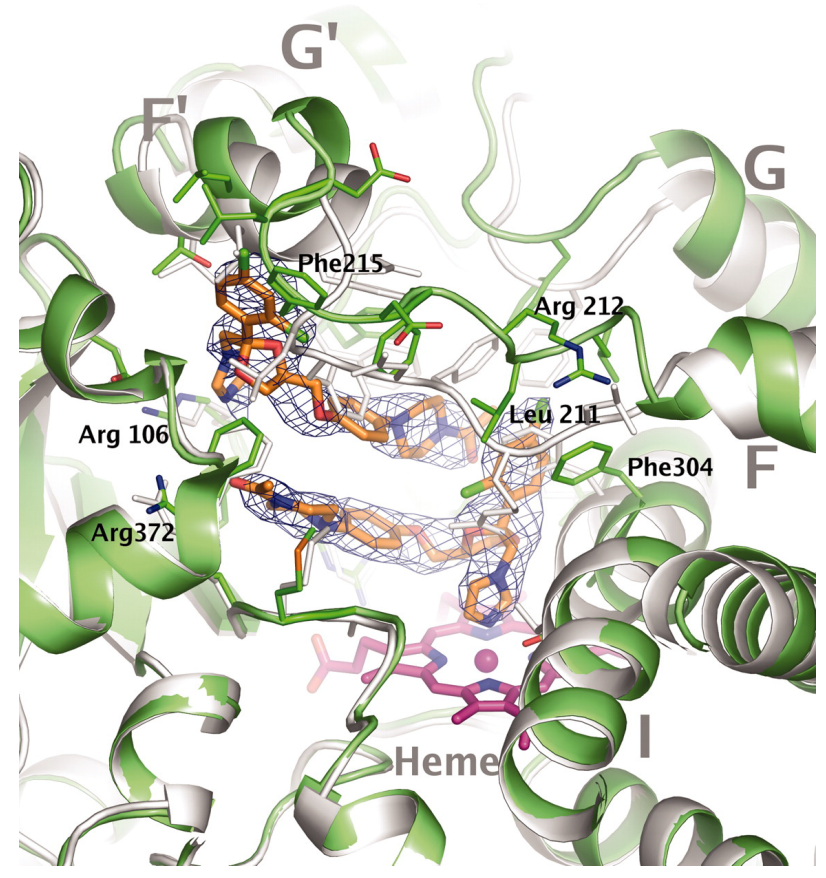

Fig. 11. Part of the structure of $P 4503 A 4$ bound to two molecules of ketoconazole (Protein Data Bank 2VOM). The two molecules of ketoconazole are indicated in red/orange, and the heme is in magenta. The mesh indicates ketoconazole electron density (Ekroos and Sjögren, 2006). Note the proximity of an imidazole nitrogen of one ketoconazole molecule to the heme iron atom (magenta sphere). The F, $F^{\prime}, G, G^{\prime}$, and I helices are shown. Reprinted from Proc. Natl. Acad. Sci. U.S.A., Vol. 103, Ekroos, M. and Sjögren, T., Structural basis for ligand promiscuity in cytochrome P450 3A4, pages 13682-13687 (Ekroos and Sjögren, 2006), Copyright (2006), with permission from National Academy of Sciences.

The role of P450 3A4 explains the interactions with erythromycin, ketoconazole, and other drugs that led the U.S. FDA to first add a "Black Box" warning in 1992 and to eventually recall the drug in 1997. Other antihistamines without the hERG issue were developed, including loratidine.

Today new chemical entities are screened to establish roles of individual enzymes, particularly P450s, in metabolism and to predict what drug-drug interactions might occur. In addition, routine hERG screening is now done in many pharmaceutical companies.

Fexofenadine, the final oxidation product, is not a hERG ligand and has almost as much affinity for the $\mathrm{H} 1$ receptor as terfenadine. Being devoid of the negative aspects (and even having a more favorable cLogP value), it was developed (as Allegra $^{\circledR}$ ) and is still marketed today (Guengerich, 2014).

\section{GESTODENE}

Gestodene is a "third-generation" progestin used in oral contraceptives (Fig. 13). It was discovered in 1975 and is used in several countries but was never approved in the United States. It is one of the lowest dose progestins, apparently because it is a very potent agonist of the progesterone receptor. Oral contraceptives also include $\mathrm{EE}_{2}$ as the estrogenic component. 


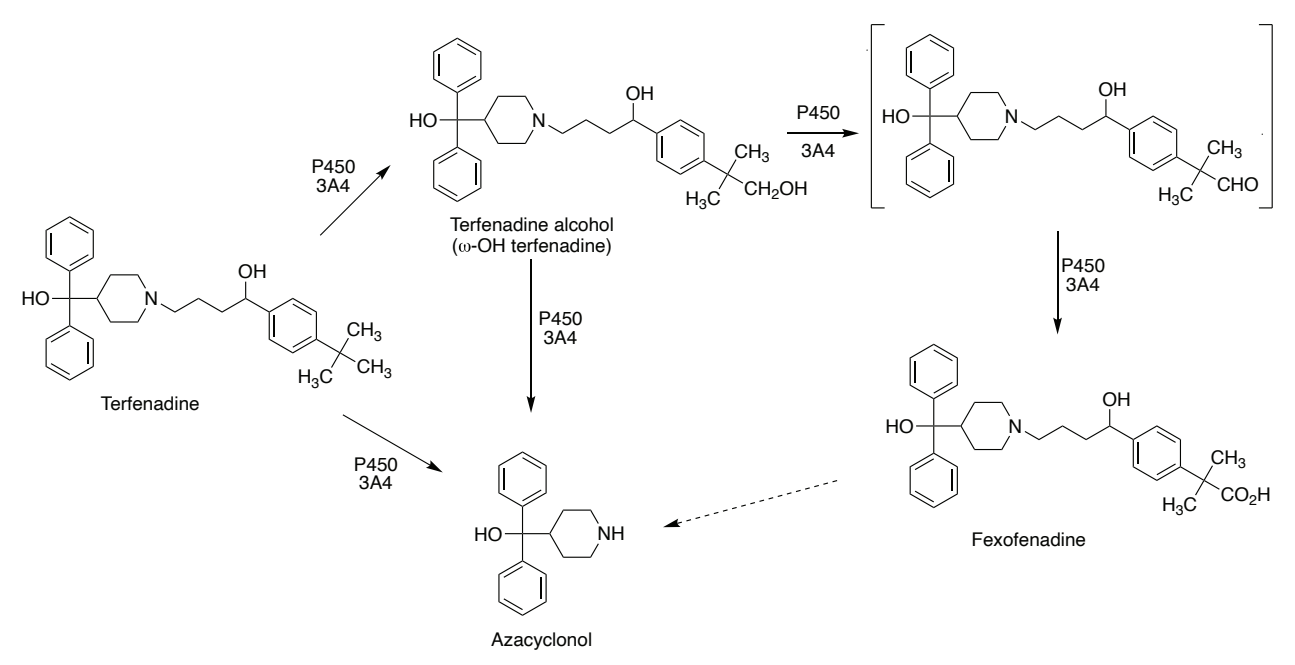

Fig. 12. Metabolism of terfenadine (Yun et al., 1993; Thompson and Oster, 1996; Guengerich, 2014). All steps are catalyzed primarily by P450 3A4.
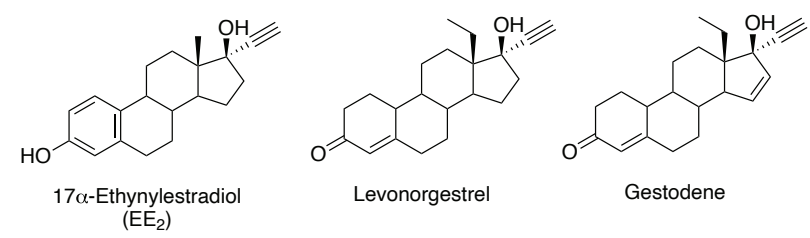

Fig. 13. Structures of some $17 \alpha$-acetylenic steroids used in oral contraceptives.

$\mathrm{EE}_{2}$ (Guengerich, 1988) and several other 17-acetylenic steroids (Ortiz de Montellano et al., 1979; Guengerich, 1990a) are mechanism-based inactivators of P450s, including P450 3A4, the enzyme involved in the 2-hydroxylation of $E_{2}$ (Guengerich, 1988).

Of a series of acetylenic contraceptive steroids tested, gestodene was the most potent in terms of inactivating P450 3A4 (Guengerich, 1990a). The inactivation was highly selective for P450 3A4 (Guengerich, 1990a). The presence of the 15,16 -double bond is important, in that the rate of inactivation of P450 3A4 by gestodene is 5-fold faster than levonorgesterol (Fig. 13). In in vitro experiments, gestodene has a $k_{\text {inactivation }} / K_{\mathrm{i}}$ ratio $\geq 10$-fold higher than $E_{2}$ in inhibiting P450 3A4 irreversibly (Guengerich, 1990a). In vivo, formulations containing both gestodene and $\mathrm{EE}_{2}$ lead to an increased $C_{\mathrm{p}, \max }$ and $\mathrm{AUC}$ of $\mathrm{EE}_{2}$ with time ( $50 \%$ over 21 days) (Kuhl et al., 1988). The major pathways of metabolism of gestodene itself involve reduction of the 3-keto group and C1, C6, and C11 hydroxylation (Kuhl et al., 1995), probably by P450 3A4 (Ward and Back, 1993). During repeated use, the pharmacokinetics of gestodene also change. Both of these changes may be related to the inhibition of P450 3A4 by gestodene (Kuhl et al., 1988; Guengerich, 1990b; Kuhl et al., 1995). However, the amount of P450 3A4 in a human liver far exceeds the amount of gestodene used each day, as noted earlier (Guengerich, 1990a). It has also been shown that the in vivo clearance of midazolam was not considerably modified by administration of gestodene (Palovaara et al., 2000). However, in vivo midazolam oxidation (following oral administration) is regarded to be indicative of hepatic
P450 3A4. One explanation is that the metabolism of $E_{2}$ and gestodene is primarily intestinal and that gestodene inactivates that pool of P450 3A4 but not that in liver, as seen with grapefruit juice and bergamottin (Paine et al., 2004). It is of interest that women taking oral contraceptives containing gestodene are 5-6 times more likely to develop venous thromboembolism than women not using contraceptive pills and 1.6 times as likely compared to those taking contraceptives containing levonorgesterol (Fig. 13) (Lidegaard et al., 2011). How this might be related to P450 3A4 inactivation is not clear.

\section{BERGAMOTTIN}

In 1990 a classical clinical drug interaction study led to an unexpected finding. An ethanol interaction study was done with the anti-hypertensive drug felodipine, a dihydropyridine calcium channel blocker. In these studies, fruit juice is often used to mask any taste of alcohol in order to prevent subjects from knowing what they were consuming. There was no effect of ethanol but grapefruit juice itself led to a dramatic increase in the AUC for orally administered felodipine (Edgar et al., 1990; Bailey et al., 1991). Subsequent studies showed similar AUC increases for several other orally administered P450 3A4 substrates (Bailey et al., 1993) (one of which is felodipine (Guengerich et al., 1991)). This effect was not seen with orange juice but could later be demonstrated with Seville orange juice and starfruit juice (Malhotra et al., 2001).

The search for grapefruit-specific natural products led to examination of naringenin but this was a weak inhibitor (Guengerich and Kim, 1990). Ultimately the furanocoumarin bergamottin was implicated (He et al., 1998). The mechanism is now known in detail, including the site of P450 3A4 that is modified (Fig. 14).

The phenomenon is now well-known, and many P450 3A4 substrates have warnings in their labels. Although this phenomenon has now been recognized for 30 years, apparently there have been no reported fatalities. The amount of bergamottin in a large serving of grapefruit juice (or grapefruit itself) is enough to produce a sizeable effect on AUC, but the phe- 

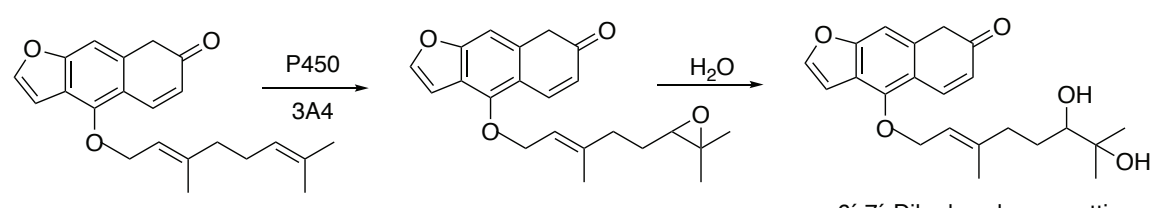

Bergamottin

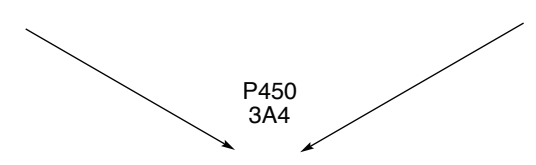

$6^{\prime}, 7^{\prime}$-Dihydroxybergamottin

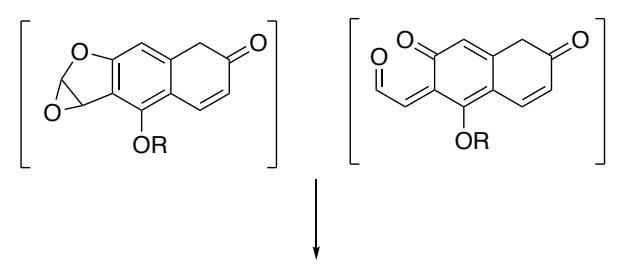
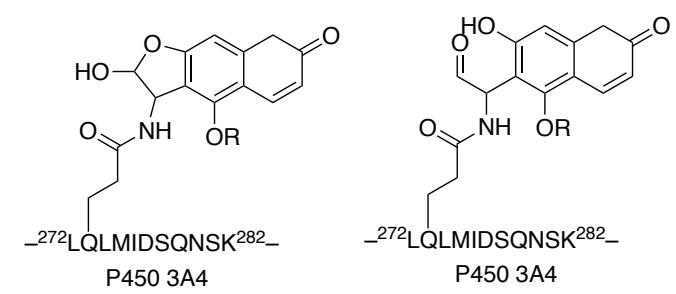

Fig. 14. Inactivation of P450 3A4 by bergamottin and position of covalent binding (He et al., 1998; Lin et al., 2012; Bailey et al., 2013; Guengerich, 2020).

nomenon appears to be largely restricted to drugs that show extensive first-pass intestinal clearance (Schmiedlin-Ren et al., 1997). P450 3A4 is the major P450 in the human small intestine (Paine et al., 2005) but the amount of it there is only a few percent of that in the liver (Guengerich, 1990a). Presumably even if a large fraction of the P450 3A4 in the small intestine is inactivated, the hepatic P450 3A4 can oxidize the fraction that enters the liver through portal circulation.

The discovery of the inhibitory effect of a natural product in food was rather serendipitous (Dresser et al., 2000) but there are probably similar compounds in foods that have yet to be discovered (Goosen et al., 2004). Herbal medicines and dietary supplements are not innocuous, e.g. St. John's wort contains the powerful PXR inducer hyperforin (Moore et al., 2000 ) and searches are in order for other inhibitors in natural products (Paine et al., 2018).

\section{PRACTICAL ISSUES IN DEALING WITH P450 INHIBITION}

As molecules are discovered with biological activity in a pharmaceutical program, early screening for P450 inhibition is often done to help stratify the compounds for further consideration. With the current knowledge of marker activities, it is possibly to do screening rapidly. A sequential approach such as that shown in Table 4 is often used, although assays for time-dependent inhibition may often precede determination of $K_{\mathrm{i}}$ values (the design for $K_{\mathrm{i}}$ determination will differ in a timedependent reaction). These screens are done in in vitro with either recombinant human enzymes or with cells or extracts of human tissues.

How does one deal with the results of such studies, and how much inhibition is a problem? A simplified approach is outlined in Fig. 15 (Obach et al., 2005; Shou and Dai, 2008). The predicted change in the exposure (AUC) for a drug is a function of the concentration of the inhibitor (I) and its $K_{\mathrm{i}}$ value. If multiple P450s (CYPs) are involved in the disposition of a "victim" drug, the fraction of the metabolism attribute to each

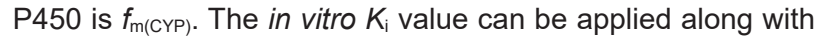
the inhibitor concentration. What is important is the unbound plasma concentration of the inhibitory drug. This analysis may seem straightforward, but one of the major issues is predicting what the plasma concentration of a new drug will be when used in patients. Obviously it is desirable to develop drugs with high efficacy in order to keep dosages lower and avoid drug-drug interactions.

A practical flow chart that came out of an FDA draft is presented in Fig. 16. The right side of Fig. 16 deals with issues of drug inhibition. In some cases dose adjustment may be in order, but that can result in a loss of drug efficacy. Another flow chart from the same FDA Draft Guidance is shown in Fig. 17 , which includes mention of a "sensitive" probe substrate. Some drugs are more sensitive to interference from inhibitors than others, and in turn some of these have narrow therapeutic windows (Table 5). That is, there are potentially dangerous consequences of having a concentration of the drug either to low or too high. A classic example is warfarin. Too low a level of this anti-coagulant leads to risk of stroke but too high a level can cause dangerous hemorrhaging.

The FDA has classified inhibitors on the basis of $A \cup C_{R}$, the ratio of $A \cup C$ without inhibitor compared to AUC with the in- 


$$
\begin{aligned}
& \frac{\mathrm{AUC}_{\text {inhibited }}}{\mathrm{AUC}_{\text {control }}}=\frac{1}{1+\frac{[]_{\text {in vitro }}}{K_{\mathrm{i}}}} \quad \text { (i.e., } 50 \% \text { inhibition when }[\mathrm{I}]=K_{\mathrm{i}} \text { ) } \\
& \frac{\mathrm{Cl}_{\text {control }}}{\mathrm{Cl}_{\text {inhibited }}}=\frac{A U C_{\text {inhibited }}}{A U C_{\text {control }}}=\frac{1}{\left[\frac{\mathrm{f}_{\mathrm{m}(\mathrm{CYP})}}{1+\frac{[]_{\text {in vitro }}}{K_{\mathrm{i}}}}\right]+\left[1-\mathrm{f}_{\mathrm{m}(\mathrm{CYP})}\right]} \\
& \text { In principle it follows that: } \frac{\mathrm{AUC}_{\text {inhibited }}}{\mathrm{AUC}_{\text {control }}}=\frac{1}{1+\frac{\left[I_{\text {plasma }}\right.}{K_{\mathrm{i}}}}
\end{aligned}
$$

Fig. 15. Formulae used to estimate in vivo inhibition parameters from in vitro measurements (Obach et al., 2005). AUC: area under the curve; I, inhibitor (in vitro or plasma concentration); $C L$ : clearance; $\mathrm{f}_{\mathrm{m}(\mathrm{CYP})}$, fraction of the clearance of the drug catalyzed by a particular P450 enzyme (CYP).

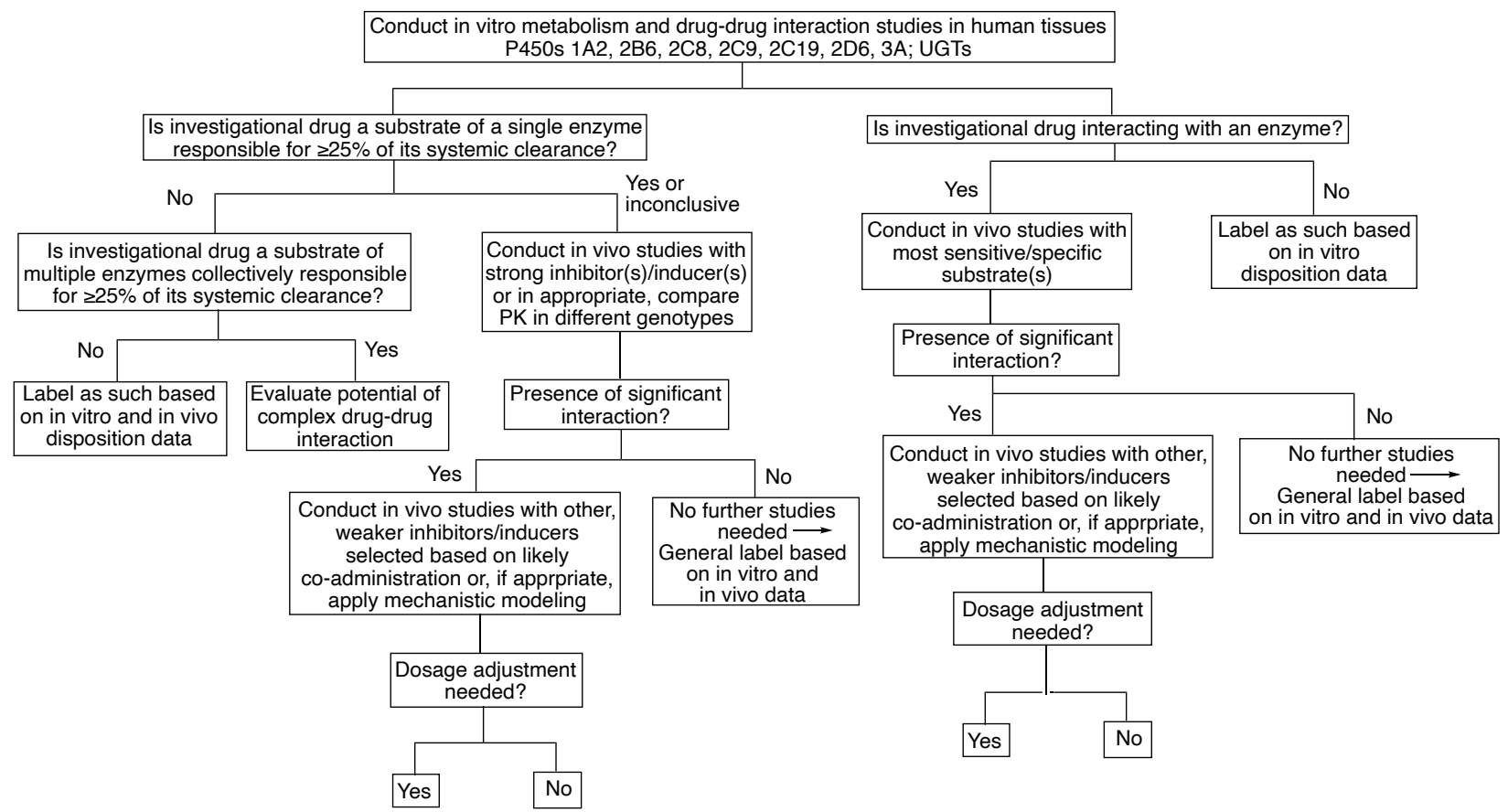

Fig. 16. An FDA decision tree scheme for metabolism-based drug-drug interaction studies (FDA, 2012).

hibitor (Fig. 17). An $\mathrm{AUC}_{\mathrm{R}}$ of $1.25-2$ is generally considered to indicate a weak inhibitor, an $A \cup C_{R}$ of $2-5$ defines a moderate inhibitor, and a drug that yields an $\mathrm{AUC}_{\mathrm{R}}>5$ is a strong inhibitor. Strong inhibitors are generally avoided unless they have good efficacy in a disease for which no other treatments are available. For instance, a drug that cures pancreatic cancer will face fewer regulatory hurdles than another new antihistamine or statin.

A flow chart developed in a pharmaceutical company (Pfizer) is shown in Fig. 18 (Obach et al., 2005). It has similarity to the FDA approaches (Fig. 16, 17). Again, the overall goal is to use resources wisely, doing the right experiments at the right time to address the potential interactions that a new drug might or might not have when introduced to the market and used widely.

\section{DRUGS DESIGNED TO INHIBIT P450S}

Most of the discussion in this review has been about avoid- 


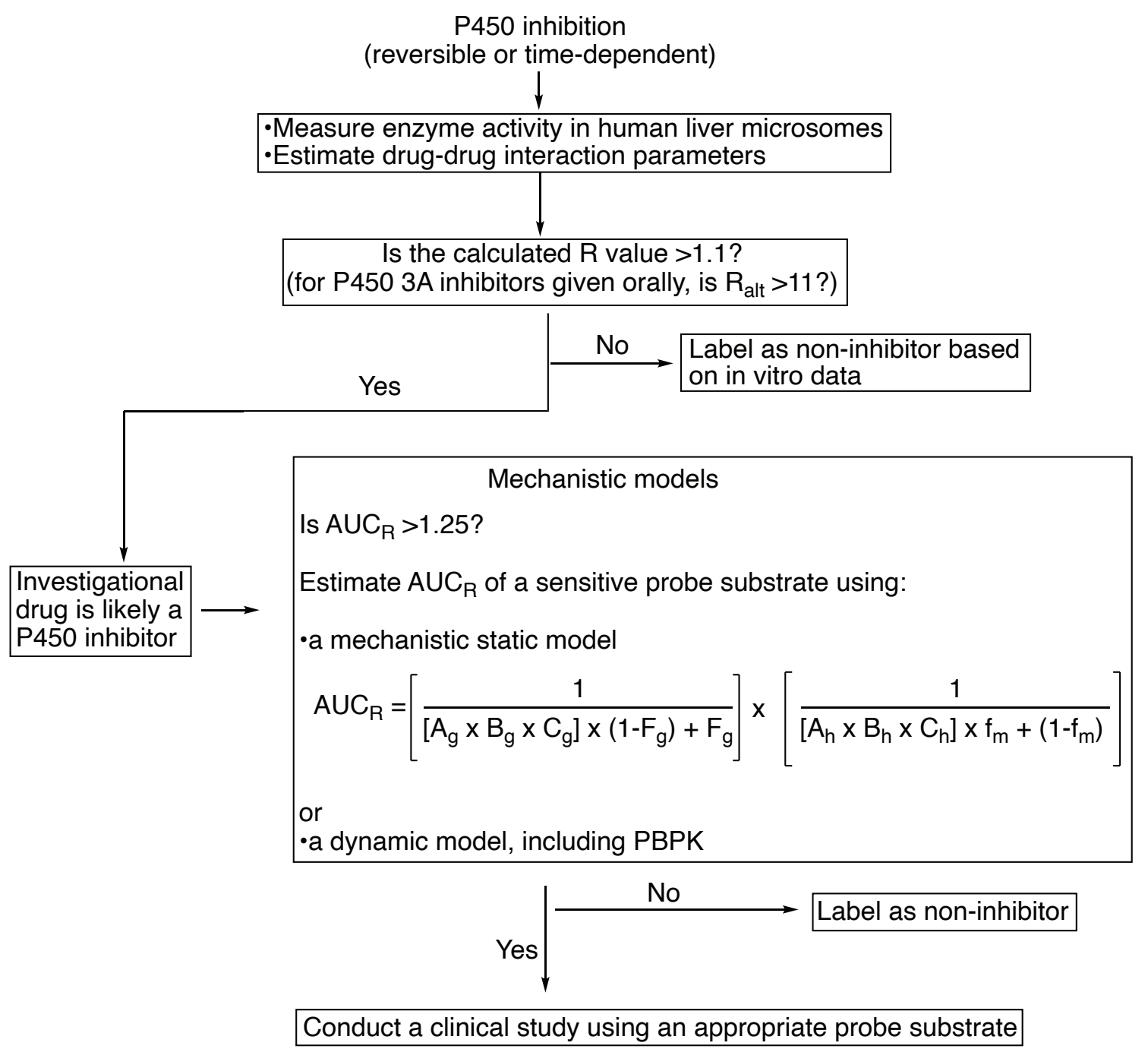

Fig. 17. An FDA general scheme of model-based prediction. In this scheme (FDA, 2012), the investigational drug (and any metabolite present at $\geq 25 \%$ of the parent drug AUC) is considered as an interacting drug with P450 enzymes. TDI: time-dependent inhibition; DDI: drug-drug interaction; $A \cup C_{R}\left(A \cup C_{\text {ratio }}\right)$ : $A \cup C_{\text {with drug }} / A \cup C_{\text {without drug }} ; R=1+\left([I] / K_{i}\right)$. For $R_{\text {alt }}$ (for oral dosage of $P 4503 A 4$ inhibitors), I=I $I_{\text {gut }}=m_{0}$ molar dose/250 mL. For the calculation of $\mathrm{AUC}_{\mathrm{R}}, \mathrm{A}, \mathrm{B}$, and $\mathrm{C}$ denote terms for time-dependent inhibition, induction, and reversible inhibition, respectively, in the gut (subscript $g$ ) or liver (subscript $h$ ). $F_{g}$ is the fraction of the drug escaping first-pass intestinal metabolism, and $f_{m}$ is the fractional contribution of a particular P450 (e.g., 3A4) to the metabolism of the drug in the liver (Fahmi et al., 2009). A is a function of the rate of degradation of the P450 $\left(k_{\text {deg }}\right)$ and the rate constant for the time-dependent inhibition $\left(k_{\text {inactivation }}\right)$, B is a function of parameters associated with induction of the particular P450, and $\mathrm{C}$ is a simple ratio of the free inhibitor concentration and $K_{\mathrm{i}}(\mathrm{Fig}$. 15) (Fahmi et al., 2009).

ing drugs that inhibit P450s. However, in at least four cases, human P450s are well-established drug targets (Table 6). Although it may not seem logical to inhibit human P450s, particularly those involved in the biosynthesis of important biological molecules, sometimes overproduction is an issue or even normal levels may contribute to a problem, e.g. hormonal cancer.

P450 5A1 is commonly known as thromboxane synthase and involved in thromboxane production. Thromboxane is involved in platelet formation, and accordingly inhibition of the enzyme is one approach to treating stroke and some other cardiovascular diseases. Drugs were already known before the enzyme was characterized as a cytochrome P450 and were originally used to characterize P450 5A1 (Hecker et al., 1986).
Another human P450 for which inhibition has proven to be very successful is P450 19A1, the steroid aromatase. Blocking estrogen production (or the interaction of estrogens with their receptors) has proven to be an important way to treat breast, ovarian, and uterine cancers. At least three (all thirdgeneration) drugs have been used widely and show good efficacy (Table 6).

In a similar way, P450 17A1 inhibition provides a mechanism for treating prostate cancer, an androgen-dependent cancer. The only approved drug to date is abiraterone, generally used as the acetate ester pro-drug $\left(Z^{y}\right.$ tiga $\left.^{\circledR}\right)$. Although the drug has efficacy, it has side effects because it inhibits the first step of P450 17A1 reactions, the $17 \alpha$-hydroxylation of progesterone and pregnenolone. This inhibition results in decreased 
Table 5. Examples of sensitive in vivo P450 substrates and P450 substrates with narrow therapeutic range

\begin{tabular}{|c|c|c|}
\hline $\begin{array}{l}\text { P450 } \\
\text { Enzymes }\end{array}$ & Sensitive substrates & Substrates with narrow therapeutic range \\
\hline $1 \mathrm{~A} 2$ & $\begin{array}{l}\text { Alosetron, caffeine, duloxetine, melatonin, ramelteon, } \\
\text { tacrin, tizanidine }\end{array}$ & Theophylline, tizanidine \\
\hline 2B6 & Bupropion, efavirenz & \\
\hline $2 \mathrm{C} 8$ & Repaglinide & Paclitaxel \\
\hline $2 \mathrm{C9}$ & Celecoxib & Warfarin, phenytoin \\
\hline 2C19 & Clobazam, lansoprazole, omeprazole, (S)-mephenytoin & (S)-Mephenytoin \\
\hline $3 \mathrm{~A}$ & $\begin{array}{l}\text { Alfentanil, aprepitant, budesonide, buspirone, conivap- } \\
\text { tan, darifenacin, darunavir, dasatinib, dronedarone, } \\
\text { eletriptan, eplerenone, everolimus, felodipine, indinavir, } \\
\text { fluticasone, lopinavir, lovastatin, lurasidone, maravi- } \\
\text { roc, midazolam, nisoldipine, quetiapine, sqquinavir, } \\
\text { sildenafile, simvastatin, sirolimus, tolvaptan, tipranair, } \\
\text { triazolam, ticagrelor, vardenafil }\end{array}$ & $\begin{array}{l}\text { Alfentanil, astemizole, cisapride, cyclosporine, dihydroergot- } \\
\text { amine, ergotamine, fentanyl, pimozide, quinidine, sirolimus, } \\
\text { tacrolimus, terfenadine }\end{array}$ \\
\hline 2D6 & $\begin{array}{l}\text { Atomoxetine, desipramine, dextromethorphan, metopro- } \\
\text { lol, nebivolol, perphenazine, tolterodine, venlafaxsine }\end{array}$ & Thioridazine, pimozide \\
\hline
\end{tabular}

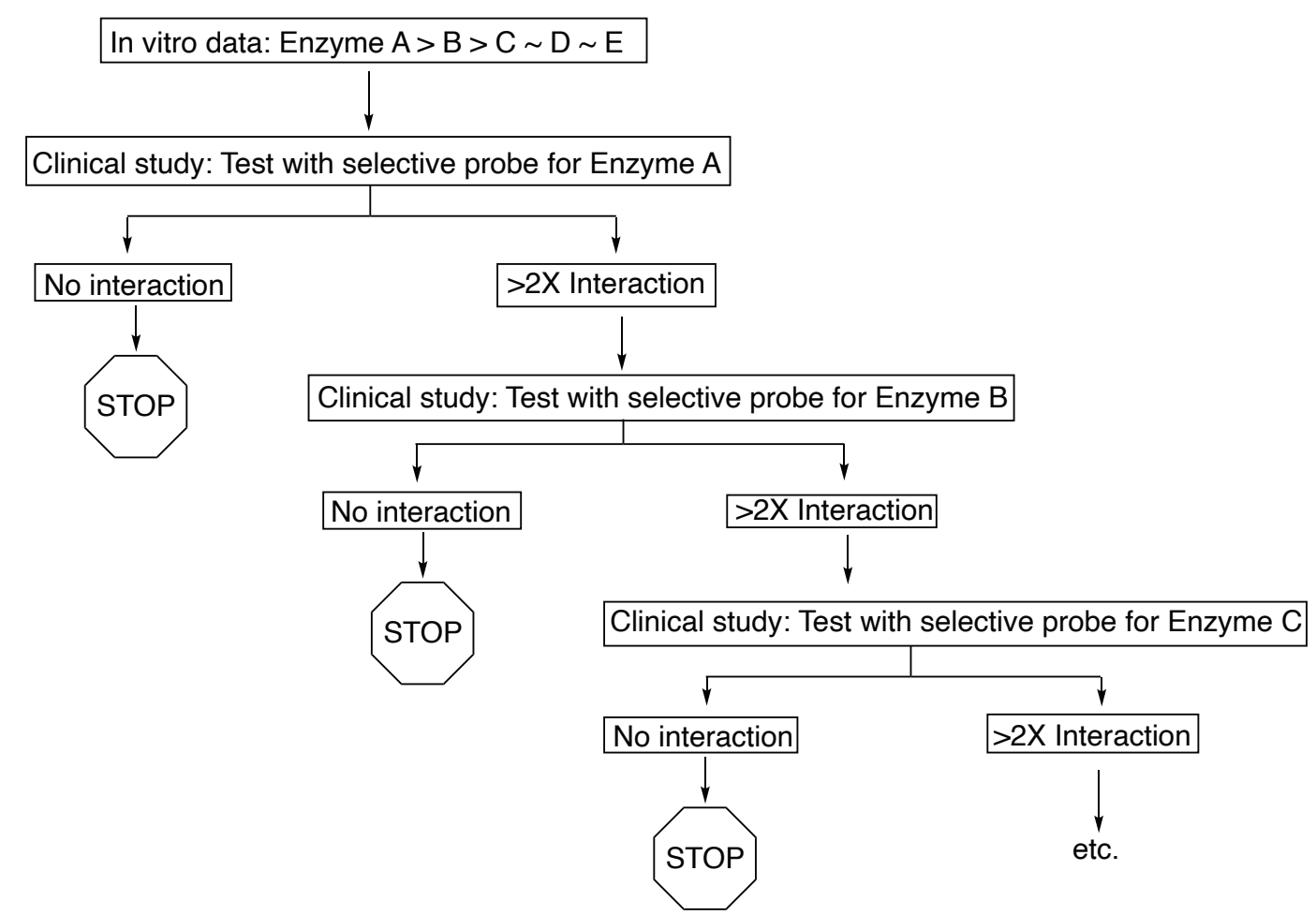

Fig. 18. A pharmaceutical industry schematic rank-order approach to drug interaction studies (Obach et al., 2005). The top section indicates the rank order of metabolism of the drug by individual enzymes.

levels of the $17 \alpha$-hydroxy steroids that are needed to produce cortisol and aldosterone, precluding patients to hyperkalemia and hypertension, which can only be partially alleviated by supplemental prednisone (Mostaghel and Nelson, 2008; Attard et al., 2012). An ideal drug would inhibit only the lyase step and not the hydroxylation, but this may not be feasible with an active site that must accommodate both a substrate and an inhibitor.

A number of drugs, including mifepristone (Chu et al., 2001), have been used to inhibit adrenal P450 11B1 in treating Cushing's disease, which is a syndrome involving overproduction of cortisol (Boscaro et al., 2000; Yin et al., 2012; Emmerich et al., 2013, 2017).

P450 51 enzymes are involved in $14 \alpha$-demethylation of ste- 
Table 6. P450s as drug targets

Currently in clinical practice
P450 5A1 (anti-platelet drugs, inhibit thromboxane production)
Pictamide
Riogrel
Ozagrel
Furegrelate
P450 19A1 (breast and other hormonal cancers)
Exemestane
Anastrozole
Letrozole
P450 17A1 (prostate cancer)
Abiraterone
P450 11B1 (Cushing's disease)
Mifepristone
P450 51 (anti-fungal, inhibit fungal P450s)
Ketoconazole
Fluconazole
Itraconazole
Vorconazole
Posaconazole
Isavuconazole
Mifepristone
Discovery and development programs
P450 4A11 (hypertension)
P450 11A1 (prostate cancer)
P450 11B2 (hypertension)
P450 24A1 (increase vitamin $\mathrm{D}_{3}$ levels)
P450 26A1 (increase vitamin A levels)
P450 26B1 (increase vitamin A levels)

rols. In mammals, P450 51A1 is a lanosterol $14 \alpha$-demethylase, catalyzing a key step in the synthesis of cholesterol. This enzyme has been considered as a target for cancer treatment (Friggeri et al., 2019), but in general human P450 51A1 is not considered a drug target (statins are more effective drugs, targeting HMG CoA-reductase). Fungi and yeasts also have P450 Family 51 enzymes, needed for the production of ergosterol for membrane synthesis. This has proven to be a major target for anti-fungals (Table 6), which are used to treat simple problems (e.g., athlete's foot-tinea pedis) as well as life-threatening systemic fungal infections common in immunocompromised individuals (Chen et al., 2020). P450 51 enzymes are also targets being developed in treatments for various parasites, e.g. trypanosomosis, leishmania (Lepesheva et al., 2004; Lepesheva and Waterman, 2007; Friggeri et al., 2014).

Other human P450 targets have been proposed for various disease states (e.g., P450s 4A11, 11A1, 11B2, 24A1, 26A1, 26B1) (Table 6) but have not been developed. Finally, another area of long-term interest is the development of inhibitors of $\mathrm{P} 450$ s that block the bioactivation of carcinogens as cancer chemopreventive agents (Conney, 2003), but only limited success has been achieved. One issue is that many of these enzymes also detoxicate the same carcinogens (Rendic and Guengerich, 2012; Lingappan et al., 2014; Uno et al., 2014).
P450 2A6, for instance, has been considered as a target because of its role in the metabolism of nicotine, with the idea that inhibition of nicotine metabolism would cause smokers to use fewer cigarettes (Sellers et al., 2000; Yano et al., 2006).

\section{ACKNOWLEDGMENTS}

Thanks are extended to $\mathrm{K}$. Trisler for assistance in preparation of the manuscript. P450 research in the author's laboratory is supported by National Institutes of Health grant R01 GM118122. The content is solely the responsibility of the author and does not necessarily represent the official view of the National Institutes of Health.

\section{REFERENCES}

Abeles, R. H. and Maycock, A. L. (1976) Suicide enzyme inactivators. Acct. Chem. Res. 9, 313-319.

Albertolle, M. E., Kim, D., Nagy, L. D., Yun, C. H., Pozzi, A., Savas, U., Johnson, E. F. and Guengerich, F. P. (2017) Heme-thiolate sulfenylation of human cytochrome P450 4A11 functions as a redox switch for catalytic inhibition. J. Biol.Chem. 292, 11230-11242.

Albertolle, M. E., Phan, T. T. N., Pozzi, A. and Guengerich, F. P. (2018) Sulfenylation of human liver and kidney microsomal cytochromes P450 and other drug-metabolizing enzymes as a response to redox alteration. Mol. Cell. Proteomics 17, 889-900.

Albertolle, M. E., Glass, S. M., Trefts, E. and Guengerich, F. P. (2019) Isotopic tagging of oxidized and reduced cysteines (iTORC) for detecting and quantifying sulfenic acids, disulfides, and free thiols in cells. J. Biol. Chem. 294, 6522-6530.

Alyamani, M., Li, Z. F., Upadhyay, S. K., Anderson, D. J., Auchus, R. J. and Sharifi, N. (2017) Development and validation of a novel LC-MS/MS method for simultaneous determination of abiraterone and its seven steroidal metabolites in human serum: innovation in separation of diastereoisomers without use of a chiral column. J. Steroid Biochem. Mol. Biol. 172, 231-239.

Attard, G., Reid, A. H., Auchus, R. J., Hughes, B. A., Cassidy, A. M., Thompson, E., Oommen, N. B., Folkerd, E., Dowsett, M., Arlt, W. and de Bono, J. S. (2012) Clinical and biochemical consequences of CYP17A1 inhibition with abiraterone given with and without exogenous glucocorticoids in castrated men with advanced prostate cancer. J. Clin. Endocrinol. Metab. 97, 507-516.

Auchus, R. J. and Miller, W. L. (2015) P450 enzymes in steroid processing. In Cytochrome P450: Structure, Mechanism, and Biochemistry (4th ed.) (P. R. Ortiz de Montellano, ed.), pp. 851-879. Springer, New York.

Bailey, D. G., Edgar, B., Spence, J. D., Munzo, C. and Arnold, J. M. O. (1990) Felodipine and nifedipine interactions with grapefruit juice. Clin. Pharmacol. Ther. 47, 180.

Bailey, D. G., Spence, J. D., Munoz, C. and Arnold, J. M. O. (1991) Interaction of citrus juices with felodipine and nifedipine. Lancet 337, 268-269.

Bailey, D. G., Freeman, D. J., Melendez, L. J., Kreeft, J. H., Edgar, B. and Carruthers, S. G. (1993) Quinidine interaction with nifedipine and felodipine: pharmacokinetic and pharmacodynamic evaluation. Clin. Pharmacol. Ther. 53, 354-359.

Bailey, D. G., Dresser, G. and Arnold, J. M. (2013) Grapefruit-medication interactions: forbidden fruit or avoidable consequences? Can. Med. Assoc. J. 185, 309-316.

Bhutani, P., Joshi, G., Raja, N., Bachhav, N., Rajanna, P. K., Bhutani, H., Paul, A. T. and Kumar, R. (2021) US FDA approved drugs from 2015-June 2020: a perspective. J. Med. Chem. 64, 2339-2381.

Bjornsson, T. D., Callaghan, J. T., Einolf, H. J., Fischer, V., Gan, L., Grimm, S., Kao, J., King, S. P., Miwa, G., Ni, L., Kumar, G., McLeod, J., Obach, R. S., Roberts, S., Roe, A., Shah, A., Snikeris, F., Sullivan, J. T., Tweedie, D., Vega, J. M., Walsh, J. and Wrighton, S. A. (2003a) The conduct of in vitro and in vivo drug-drug inter- 
action studies: a Pharmaceutical Research and Manufacturers of America (PhRMA) perspective. Drug Metab. Dispos. 31, 815-832.

Bjornsson, T. D., Callaghan, J. T., Einolf, H. J., Fischer, V., Gan, L., Grimm, S., Kao, J., King, S. P., Miwa, G., Ni, L., Kumar, G., McLeod, J., Obach, S. R., Roberts, S., Roe, A., Shah, A., Snikeris, F., Sullivan, J. T., Tweedie, D., Vega, J. M., Walsh, J. and Wrighton, S. A. (2003b) The conduct of in vitro and in vivo drug-drug interaction studies: a PhRMA perspective. J. Clin. Pharmacol. 43, 443-469.

Bolt, H. M., Bolt, M. and Kappus, H. (1977) Interaction of rifampicin treatment with pharmacokinetics and metabolism of ethinyloestradiol in man. Acta Endocrinol. 85, 189-197.

Boscaro, M., Barzon, L. and Sonino, N. (2000) The diagnosis of Cushing's syndrome: atypical presentations and laboratory shortcomings. Arch. Int. Med. 160, 3045-3053.

Chen, L., Krekels, E. H. J., Verweij, P. E., Bui, J. B., Knibbe, C. A. J. and Brüggemann, R. J. M. (2020) Pharmacokinetics and pharmacodynamics of posaconazole. Drugs 80, 671-695.

Cheong, E. J. Y., Nair, P. C., Neo, R. W. Y., Tu, H. T., Lin, F., Chiong, E., Esuvaranathan, K., Fan, H., Szmulewitz, R. Z., Peer, C. J., Figg, W. D., Chai, C. L. L., Miners, J. O. and Chan, E. C. Y. (2020) Slow-, tightbinding inhibition of CYP17A1 by abiraterone redefines its kinetic selectivity and dosing regimen. J. Pharmacol. Exp. Ther. 374, 438-451.

Child, S. A. and Guengerich, F. P. (2020) Multistep binding of the nonsteroidal inhibitors orteronel and seviteronel to human cytochrome P450 17A1 and relevance to inhibition of enzyme activity. J. Med. Chem. 63, 6513-6522.

Chu, J. W., Matthias, D. F., Belanoff, J., Schatzberg, A., Hoffman, A. R. and Feldman, D. (2001) Successful long-term treatment of refractory Cushing's disease with high-dose mifepristone (RU 486). J. Clin. Endocrinol. Metab. 86, 3568-3573.

Conney, A. H. (2003) Enzyme induction and dietary chemicals as approaches to cancer chemoprevention: the Seventh DeWitt S. Goodman Lecture. Cancer Res. 63, 7005-7031.

Correia, M. A. and Hollenberg, P. F. (2015) Inhibition of cytochrome P450 enzymes. In Cytochrome P450: Structure, Mechanism, and Biochemistry (4th ed.) (P. R. Ortiz de Montellano, ed.), pp. 177-259. Springer, New York.

DeVore, N. M. and Scott, E. E. (2012) Structures of cytochrome P450 $17 \mathrm{~A} 1$ with prostate cancer drugs abiraterone and TOK-001. Nature 482, 116-119.

Dixon, M. and Webb, E. C. (1964) Enzymes (2nd ed.). Longman's, Green, London.

Dresser, G. K., Spence, J. D. and Bailey, D. G. (2000) Pharmacokinetic-pharmacodynamic consequences and clinical relevance of cytochrome P450 3A4 inhibition. Clin. Pharmacokinet. 38, 41-57.

Edgar, B., Bailey, D. G., Bergstrand, R., Johnsson, G. and Lurje, L. (1990) Formulation dependent interaction between felodipine and grapefruit juice. Clin. Pharmacol. Ther. 47, 181.

Ekroos, M. and Sjögren, T. (2006) Structural basis for ligand promiscuity in cytochrome P450 3A4. Proc. Natl. Acad. Sci. U.S.A. 103 13682-13687.

Emmerich, J., Hu, Q., Hanke, N. and Hartmann, R. W. (2013) Cushing's syndrome: development of highly potent and selective $\mathrm{CY}$ P11B1 inhibitors of the (pyridylmethyl)pyridine type. J. Med. Chem. 56, 6022-6032.

Emmerich, J., van Koppen, C. J., Burkhart, J. L., Hu, Q., Siebenburger, L., Boerger, C., Scheuer, C., Laschke, M. W., Menger, M. D. and Hartmann, R. W. (2017) Lead optimization generates CYP11B1 inhibitors of pyridylmethyl isoxazole type with improved pharmacological profile for the treatment of Cushing's disease. J. Med. Chem. 60, 5086-5098.

Eng, H., Tseng, E., Cerny, M. A., Goosen, T. C. and Obach, R. S. (2021) Cytochrome P450 3A time-dependent inhibition assays are too sensitive for identification of drugs causing clinically significant drug-drug interactions: a comparison of human liver microsomes and hepatocytes and definition of boundaries for inactivation rate constants. Drug Metab. Dispos. 49, 442-450.

Fahmi, O. A., Hurst, S., Plowchalk, D., Cook, J., Guo, F., Youdim, K., Dickins, M., Phipps, A., Darekar, A., Hyland, R. and Obach, R. S. (2009) Comparison of different algorithms for predicting clinical drug-drug interactions, based on the use of CYP3A4 in vitro data: predictions of compounds as precipitants of interaction. Drug
Metab. Dispos. 37, 1658-1666.

FDA (2012) Guidance for Industry Drug Interaction Studies — Study Design, Data Analysis, Implications for Dosing, and Labeling Recommendations. U.S. Department of Health and Human Services Food and Drug Administration, Center for Drug Evaluation and Research (CDER), February 2012 Clinical Pharmacology, Silver Spring, MD.

Fekry, M. I., Xiao, Y., Berg, J. Z. and Guengerich, F. P. (2019) A role for the orphan human cytochrome P450 2S1 in polyunsaturated fatty acid w-1 hydroxylation using an untargeted metabolomic approach. Drug Metab. Dispos. 47, 1325-1332.

Flockhart, D. A. (2007) Drug Interactions: Cytochrome P450 Drug Interaction Table. Indiana University School of Medicine. Available from: https://drug-interactions.medicine.iu.edu/ [accessed 2021 Aug 27].

Franklin, M. R. and Buening, M. K. (1974) The formation of complexes absorbing at $455 \mathrm{~nm}$ form cytochrome P450 and metabolites of compounds related to SKF 525A. Drug Metab. Dispos. 2, 386-390.

Friggeri, L., Hargrove, T. Y., Rachakonda, G., Williams, A. D., Wawrzak, Z., Di Santo, R., De Vita, D., Waterman, M. R., Tortorella, S., Villalta, F. and Lepesheva, G. I. (2014) Structural basis for rational design of inhibitors targeting Trypanosoma cruzi sterol $14 \alpha$-demethylase: two regions of the enzyme molecule potentiate its inhibition. J. Med. Chem. 57, 6704-6717.

Friggeri, L., Hargrove, T. Y., Wawrzak, Z., Guengerich, F. P. and Lepesheva, G. I. (2019) Validation of human sterol $14 \alpha$-demethylase (CYP51) druggability: structure-guided design, synthesis and evaluation of stoichiometric, functionally irreversible inhibitors. J. Med. Chem. 62, 10391-10401.

Goosen, T. C., Cillie, D., Bailey, D. G., Yu, C., He, K., Hollenberg, P. F., Woster, P. M., Cohen, L., Williams, J. A., Rheeders, M. and Dijkstra, H. P. (2004) Bergamottin contribution to the grapefruit juicefelodipine interaction and disposition in humans. Clin. Pharmacol. Ther. 76, 607-617.

Guengerich, F. P. (1988) Oxidation of $17 \alpha$-ethynylestradiol by human liver cytochrome P-450. Mol. Pharmacol. 33, 500-508.

Guengerich, F. P. (1989) Characterization of human microsomal cytochrome P-450 enzymes. Annu. Rev. Pharmacol. Toxicol. 29, 241264.

Guengerich, F. P. (1990a) Mechanism-based inactivation of human liver microsomal cytochrome P-450 IIIA4 by gestodene. Chem. Res. Toxicol. 3, 363-371.

Guengerich, F. P. (1990b) Inhibition of oral contraceptive steroid-metabolizing enzymes by steroids and drugs. Am. J. Obstet. Gynecol. 163, 2159-2163.

Guengerich, F. P. and Kim, D. H. (1990) In vitro inhibition of dihydropyridine oxidation and aflatoxin B1 activation in human liver microsomes by naringenin and other flavonoids. Carcinogenesis 11, 2275-2279.

Guengerich, F. P., Brian, W. R., Iwasaki, M., Sari, M. A., Bäârnhielm, C. and Berntsson, P. (1991) Oxidation of dihydropyridine calcium channel blockers and analogues by human liver cytochrome P-450 IIIA4. J. Med. Chem. 34, 1838-1844.

Guengerich, F. P. (2014) Cytochrome P450-mediated drug interactions and cardiovascular toxicity: the Seldane to Allegra transformation. In Predictive ADMET: Integrated Approaches in Drug Discovery and Development (J. Wang and L. Urban, Ed.), pp. 523-534. Wiley, New York.

Guengerich, F. P. (2019a) Kinetic modeling of steady-state situations in cytochrome P450 enzyme reactions. Drug Metab. Dispos. 47, 1232-1239.

Guengerich, F. P. (2019b) Cytochrome P450 research and The Journal of Biological Chemistry. J. Biol. Chem. 294, 1671-1680.

Guengerich, F. P. (2020) A history of the role of cytochrome P450 enzymes in the toxicity of drugs. Toxicol. Res. 37, 1-23.

Guengerich, F. P., McCarty, K. D. and Chapman, J. G. (2020) Kinetics of cytochrome P450 3A4 inhibition by heterocyclic drugs defines a general sequential multistep binding process. J. Biol. Chem. 296, 100223.

Guengerich, F. P., McCarty, K. D. and Chapman, J. G. (2021) Stepwise binding of inhibitors to human cytochrome P450 17A1 and relevance to kinetics of inhibition of androgen biosynthesis. J. Biol. 
Chem. 297, 100969.

Halpert, J. and Neal, R. A. (1980) Inactivation of purified rat liver cytochrome P-450 by chloramphenicol. Mol. Pharmacol. 17, 427-431.

Hardy, K. D., Wahlin, M. D., Papageorgiou, I., Unadkat, J. D., Rettie, A. E. and Nelson, S. D. (2014) Studies on the role of metabolic activation in tyrosine kinase inhibitor-dependent hepatotoxicity: induction of CYP3A4 enhances the cytotoxicity of lapatinib in HepaRG cells. Drug Metab. Dispos. 42, 162-171.

He, K., lyer, R., Hayes, R. N., Sinz, M. W., Woolf, T. F. and Hollenberg, P. F. (1998) Inactivation of cytochrome P450 3A4 by bergamottin, a component of grapefruit juice. Chem. Res. Toxicol. 11, 252-259.

Hecker, M., Haurand, M., Ullich, V. and Terao, S. (1986) Spectral studies on structure-activity relationships of thromboxane synthase inhibitors. Eur. J. Biochem. 157, 217-223.

Honig, P. K., Woosley, R. L., Zamani, K., Conner, D. P. and Cantilena, L. R., Jr. (1992) Changes in the pharmacokinetics and electrocardiographic pharmacodynamics of terfenadine with concomitant administration of erythromycin. Clin. Pharmacol. Ther. 52, 231-238.

Johnson, K. A. (2019) Kinetic Anaylsis for the New Enzymology (1st ed.). KinTek, Austin, TX.

Kramlinger, V. M., Alvarado Rojas, M., Kanamori, T. and Guengerich, F. P. (2015) Cytochrome P450 3A enzymes catalyze the O6-demethylation of thebaine, a key step in endogenous mammalian morphine biosynthesis. J. Biol. Chem. 290, 20200-20210.

Kuby, S. A. (1991) A Study of Enzymes, Vol. I, Enzyme Catalysis, Kinetics, and Substrate Binding (Vol. 7). CRC Press, Boca Raton, FL.

Kuhl, H., Jung-Hoffmann, C. and Heidt, F. (1988) Alterations in the serum levels of gestodene and SHBG during 12 cycles of treatment with $30 \mathrm{mg}$ ethinylestradiol and $75 \mathrm{mg}$ gestodene. Contraception 38, 477-486.

Kuhl, H., Jung-Hoffmann, C. and Wiegratz, I. (1995) Gestodene-containing contraceptives. Clin. Obstet. Gynecol. 38, 829-840.

Lepesheva, G. I., Nes, W. D., Zhou, W., Hill, G. C. and Waterman, M. R. (2004) CYP51 from Trypanosoma brucei is obtusifoliol-specific. Biochemistry 43, 10789-10799.

Lepesheva, G. I. and Waterman, M. R. (2007) Sterol $14 \alpha$-demethylase cytochrome P450 (CYP51), a P450 in all biological kingdoms. Biochim. Biophys. Acta 1770, 467-477.

Lidegaard, Ø., Nielsen, L. H., Skovlund, C. W., Skjeldestad, F. E. and Løkkegaard, E. (2011) Risk of venous thromboembolism from use of oral contraceptives containing different progestogens and oestrogen doses: Danish cohort study, 2001-9. BMJ 343, d6423.

Lin, H. L., Kenaan, C. and Hollenberg, P. F. (2012) Identification of the residue in human CYP3A4 that is covalently modified by bergamottin and the reactive intermediate that contributes to the grapefruit juice effect. Drug Metab. Dispos. 40, 998-1006.

Lin, H. L., Zhang, H. M. and Hollenberg, P. F. (2018) Formation of both heme and apoprotein adducts contributes to the mechanism-based inactivation of human CYP2J2 by $17 \alpha$-ethynylestradiol. Drug Metab. Dispos. 46, 813-822.

Lingappan, K., Jiang, W., Wang, L., Wang, G., Couroucli, X. I., Shivanna, B., Welty, S. E., Barrios, R., Khan, M. F., Nebert, D. W., Roberts, L. J. and Moorthy, B. (2014) Mice deficient in the gene for cytochrome P450 (CYP)1A1 are more susceptible than wild-type to hyperoxic lung injury: evidence for protective role of CYP1A1 against oxidative stress. Toxicol. Sci. 141, 68-77.

Malhotra, S., Bailey, D. G., Paine, M. F. and Watkins, P. B. (2001) Seville orange juice-felodipine interaction: comparison with dilute grapefruit juice and involvement of furocoumarins. Clin. Pharmacol. Ther. 69, 14-23.

Mansuy, D., Battioni, J. P. and Chottard, J. C. (1979) Preparation of a porphyrin-iron-carbene model for the cytochrome P450 complexes obtained upon metabolic oxidation of the insecticide synergists of the 1,3-benzodioxole series. J. Am. Chem. Soc. 101, 3971-3973.

Montané, E., Arellano, A. L., Sanz, Y., Roca, J. and Farre, M. (2018) Drug-related deaths in hospital inpatients: a retrospective cohort study. Br. J. Clin. Pharmacol. 84, 542-552.

Moore, L. G., Goodwin, B., Jones, S. A., Wisely, G. B., Serabjit-Singh, C. J., Wilson, T. M., Collins, J. L. and Kliewer, S. A. (2000) St. John's wort induces hepatic drug metabolism through activation of the pregnane X receptor. Proc. Natl. Acad. Sci. U.S.A. 97, 75007502.
Mostaghel, E. A. and Nelson, P. S. (2008) Intracrine androgen metabolism in prostate cancer progression: mechanisms of castration resistance and therapeutic implications. Best Pract. Res. Clin. Endocrinol. Metab. 22, 243-258.

Mueller, G. C. and Miller, J. A. (1948) The metabolism of 4-dimethylaminoazobenzene by rat liver homogenates. J. Biol. Chem. 176, 535-544.

Obach, R. S., Walsky, R. L., Venkatakrishnan, K., Houston, J. B. and Tremaine, L. M. (2005) In vitro cytochrome P450 inhibition data and the prediction of drug-drug interactions: qualitative relationships, quantitative predictions, and the rank-order approach. Clin. Pharmacol. Ther. 78, 582-592.

Omura, T. and Sato, R. (1962) A new cytochrome in liver microsomes. J. Biol. Chem. 237, 1375-1376.

Omura, T. and Sato, R. (1964) The carbon monoxide-binding pigment of liver microsomes. I. Evidence for its hemoprotein nature. J. Biol. Chem. 239, 2370-2378.

Ortiz de Montellano, P. R. (2015) Cytochrome P450: Structure, Mechanism, and Biochemistry (4th ed.). Springer, New York.

Ortiz de Montellano, P. R., Kunze, K. L., Yost, G. S. and Mico, B. A. (1979) Self-catalyzed destruction of cytochrome P-450: covalent binding of ethynyl sterols to prosthetic heme. Proc. Natl. Acad. Sci. U.S.A. 76, 746-749.

Paine, M. F., Criss, A. B. and Watkins, P. B. (2005) Two major grapefruit juice components differ in time to onset of intestinal CYP3A4 inhibition. J. Pharmacol. Exp. Ther. 312, 1151-1160.

Paine, M. F., Shen, D. D. and McCune, J. S. (2018) Recommended approaches for pharmacokinetic natural product-drug interaction research: a NaPDI Center commentary. Drug Metab. Dispos. 46, 1041-1045.

Palovaara, S., Kivistö, K. T., Tapanainen, P., Manninen, P., Neuvonen, P. J. and Laine, K. (2000) Effect of an oral contraceptive preparation containing ethinylestradiol and gestodene on CYP3A4 activity as measured by midazolam 1'-hydroxylation. Br. J. Clin. Pharmacol. 50, 333-337.

Parkinson, A., Ogilvie, B. W., Buckley, D. B., Kazmi, F. and Parkinson, O. (2019) Biotransformation of xenobiotics. In Casarett and Doull's Toxicology: The Basic Science of Poisons (6th ed.) (C. D. Klaassen, ed.), pp. 193-399. McGraw Hill, New York.

Paulsen-Sörman, U. B., Jönsson, K. H. and Lindeke, B. G. A. (1984) Cytochrome P-455 nm complex formation in the metabolism of phenylalkylamines. 8. Stereoselectivity in metabolic intermediary complex formation with a series of chiral 2-substituted 1-phenyl2-aminoethanes. J. Med. Chem. 27, 342-346.

Petrunak, E. M., DeVore, N. M., Porubsky, P. R. and Scott, E. E. (2014) Structures of human steroidogenic cytochrome P450 17A1 with substrates. J. Biol. Chem. 289, 32952-32964.

Petrunak, E. M., Rogers, S. A., Aube, J. and Scott, E. E. (2017) Structural and functional evaluation of clinically relevant inhibitors of steroidogenic cytochrome P450 17A1. Drug Metab. Dispos. 45, 635-645.

Rangno, R. (1997) Terfenadine therapy: can we justify the risks? Can. Med. Assoc. J. 157, 37-38.

Rendic, S. and Guengerich, F. P. (2012) Contributions of human enzymes in carcinogen metabolism. Chem. Res. Toxicol. 25, 13161383.

Rendic, S. and Guengerich, F. P. (2015) Survey of human oxidoreductases and cytochrome P450 enzymes involved in the metabolism of xenobiotic and natural chemicals. Chem. Res. Toxicol. 28, 3842.

Ryan, K. J. (1959) Biological aromatization of steroids. J. Biol. Chem. 234, 268-272.

Schmiedlin-Ren, P., Edwards, D. J., Fitzsimmons, M. E., He, K., Lown, K. S., Woster, P. M., Rahman, A., Thummel, K. E., Fisher, J. M., Hollenberg, P. F. and Watkins, P. B. (1997) Mechanisms of enhanced oral availability of CYP3A4 substrates by grapefruit constituents. Drug Metab. Dispos. 25, 1228-1233.

Segel, I. H. (1975) Enzyme Kinetics. Wiley, New York.

Sellers, E. M., Kaplan, H. L. and Tyndale, R. F. (2000) Inhibition of cytochrome P450 2A6 increases nicotine's oral bioavailability and decreases smoking. Clin. Pharmacol. Ther. 68, 35-43.

Shinkyo, R. and Guengerich, F. P. (2011) Inhibition of human cyto- 
chrome P450 3A4 by cholesterol. J. Biol. Chem. 286, 1842618433.

Shou, M. and Dai, R. (2008) Analysis of in vitro cytochrome P450 inhibition in drug discovery and development. In Drug Metabolism in Drug Design and Development (D. Zhang, M. Zhu and W. G. Humphreys, Eds.), pp. 513-544. Wiley, Hoboken, NJ.

Silverman, R. B. (1995) Mechanism-based enzyme inactivators. Methods Enzymol. 249, 240-283.

Thompson, D. and Oster, G. (1996) Use of terfenadine and contraindicated drugs. JAMA 275, 1339-1341.

Uno, S., Sakurai, K., Nebert, D. W. and Makishima, M. (2014) Protective role of cytochrome P450 1A1 (CYP1A1) against benzo[a] pyrene-induced toxicity in mouse aorta. Toxicology 316, 34-42.

Ward, S. and Back, D. J. (1993) Metabolism of gestodene in human liver cytosol and microsomes in vitro. J. Steroid Biochem. Mol. Biol. 46, 235-243.

Williams, R. T. (1947) Detoxication Mechanisms (1st ed.). Wiley, New York.

Woosley, R. L., Chen, Y., Freiman, J. P. and Gillis, R. A. (1993) Mechanism of the cardiotoxic actions of terfenadine. JAMA 269, 15321536.

Woosley, R. L. (1996) Cardiac actions of antihistamines. Annu. Rev. Pharmacol. Toxicol. 36, 233-252.

Yano, J. K., Wester, M. R., Schoch, G. A., Griffin, K. J., Stout, C. D. and Johnson, E. F. (2004) The structure of human microsomal cytochrome P450 3A4 determined by X-ray crystallography to $2.05 \AA$ resolution. J. Biol. Chem. 279, 38091-38094.

Yano, J. K., Denton, T. T., Cerny, M. A., Zhang, X., Johnson, E. F. and Cashman, J. R. (2006) Synthetic inhibitors of cytochrome P-450 2A6: inhibitory activity, difference spectra, mechanism of inhibition, and protein cocrystallization. J. Med. Chem. 49, 6987-7001.

Yin, L. N., Lucas, S., Maurer, F., Kazmaier, U., Hu, Q. Z. and Hartmann, R. W. (2012) Novel imidazol-1-ylmethyl substituted 1,2,5,6-tetrahydropyrrolo 3,2,1-i,j quinolin-4-ones as potent and selective CYP11B1 inhibitors for the treatment of Cushing's syndrome. J. Med. Chem. 55, 6629-6633.

Yu, J. J., Zhou, Z., Tay-Sontheimer, J., Levy, R. H. and RagueneauMajlessi, I. (2018) Risk of clinically relevant pharmacokinetic-based drug-drug interactions with drugs approved by the US Food and Drug Administration between 2013 and 2016. Drug Metab. Dispos. 46, 835-845.

Yun, C. H., Okerholm, R. A. and Guengerich, F. P. (1993) Oxidation of the antihistaminic drug terfenadine in human liver microsomes. Role of cytochrome P-450 3A(4) in N-dealkylation and C-hydroxylation. Drug Metab. Dispos. 21, 403-409.

Zhang, D., Flint, O., Wang, L., Gupta, A., Westhouse, R. A., Zhao, W., Raghavan, N., Caceres-Cortes, J., Marathe, P., Shen, G., Zhang, Y., Allentoff, A., Josephs, J., Gan, J., Borzilleri, R. and Humphreys, W. G. (2012) Cytochrome P450 11A1 bioactivation of a kinase inhibitor in rats: use of radioprofiling, modulation of metabolism, and adrenocortical cell lines to evaluate adrenal toxicity. Chem. Res. Toxicol. 25, 556-571.

Zhu, Y., Wang, F., Li, Q., Zhu, M., Du, A., Tang, W. and Chen, W. (2014) Amlodipine metabolism in human liver microsomes and roles of CYP3A4/5 in the dihydropyridine dehydrogenation. Drug Metab. Dispos. 42, 245-249.

Zimmerlin, A., Trunzer, M. and Faller, B. (2011) CYP3A time-dependent inhibition risk assessment validated with 400 reference drugs. Drug Metab. Dispos. 39, 1039-1046. 